\title{
Hyperoside Supplementation in Preservation Media Surpasses Vitamin C Protection Against Oxidative Stress- Induced Damages in Human Spermatozoa
}

\author{
Mafalda V. Moreira ${ }^{a, b}$ Sara C. Pereirab Bárbara Guerra-Carvalho ${ }^{b, c, d}$ \\ David F. Carrageta ${ }^{b}$ Soraia Pinto Alberto Barros $^{\text {ef,g }} \quad$ Branca M. Silvah $^{\text {h }}$ \\ Pedro F. Oliveirac Marco G. Alves ${ }^{b}$
}

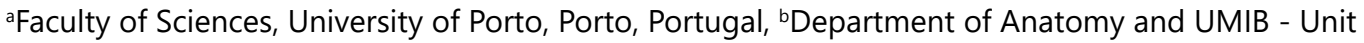
for Multidisciplinary Research in Biomedicine, ICBAS - School of Medicine and Biomedical Sciences, University of Porto, Porto, Portugal, 'QOPNA \& LAQV, Department of Chemistry, University of Aveiro, Aveiro, Portugal, 'Department of Life Sciences, Faculty of Sciences and Technology, University of Coimbra, Coimbra, Portugal, ${ }^{e}$ Centre for Reproductive Genetics Professor Alberto Barros, Porto, Portugal, 'Department of Genetics, Faculty of Medicine, University of Porto, Porto, Portugal, gi3S Instituto de Investigação e Inovação em Saúde, University of Porto, Porto, Portugal, "'University of Beira Interior, Covilhã, Portugal

\section{Key Words}

Assisted-reproduction $\cdot$ Hyperoside $•$ Vitamin C $•$ Sperm-quality

\begin{abstract}
Background/Aims: Oxidative Stress (OS) is reported as one of the main causes of male infertility. Infertile couples often resort to assisted reproductive technology (ART) to achieve parenthood. However, preparation for ART protocols increases the exposer of gametes to OS. Thus, it is crucial to find suitable preservation media that can counteract the OS-induced damages in spermatozoa. In this work, we tested and compared the efficiency of vitamin C (VC) and hyperoside (HYP) as potential antioxidant supplements for sperm preservation media. Methods: We evaluated the cytotoxicity of $\operatorname{HYP}(0,5,50,100$, and $500 \mu \mathrm{M})$ in spermatozoa. After incubation of sperm cells with VC $(600 \mu \mathrm{M})$ and HYP $(100$ and $500 \mu \mathrm{M})$, in the presence and absence of $\mathrm{H}_{2} \mathrm{O}_{2}(300 \mu \mathrm{M})$, the following parameters were assessed: total sperm motility and vitality, OS biomarkers expression, total antioxidant capacity (TAC) of the media, percentage of DNA fragmentation, mitochondrial membrane potential (MMP), and metabolite quantification of the media by proton nuclear magnetic resonance ( $\left.{ }^{1} \mathrm{H}-\mathrm{NMR}\right)$. Results: The supplementation with VC $(600 \mu \mathrm{M})$ and HYP $(100$ and $500 \mu \mathrm{M})$ did not induce
\end{abstract}

M. V. Moreira and S. C. Pereira contributed equally to this work. 
any deleterious effects to the physiology and metabolism of the spermatozoa, after 1-hour of treatment. In the presence of $\mathrm{H}_{2} \mathrm{O}_{2}(300 \mu \mathrm{M})$, both VC and HYP were able to prevent some of the deleterious effects of $\mathrm{H}_{2} \mathrm{O}_{2}$ in sperm, which were represented by an increase in sperm motility, a decrease in DNA fragmentation, and a decreasing trend in lipid peroxidation levels. However, these antioxidants were not able to prevent the decrease of MMP associated with $\mathrm{H}_{2} \mathrm{O}_{2}$ treatment, nor were able to prevent the conversion of pyruvate into acetate (a reaction promoted by $\mathrm{H}_{2} \mathrm{O}_{2}$ ). Conclusion: The supplementation of sperm preservation media with VC and HYP could be beneficial for the preservation of sperm physiology. From the antioxidant conditions tested, the supplementation of media with HYP $(100 \mu \mathrm{M})$ demonstrated the best results regarding sperm preservation, evidencing the higher antioxidant capacity of HYP compared to VC. Nevertheless, none of the antioxidants used was able to prevent the metabolic alterations promoted by $\mathrm{H}_{2} \mathrm{O}_{2}$ in spermatozoa.

(C) 2022 The Author(s). Published by Cell Physiol Biochem Press GmbH\&Co. KG

\section{Introduction}

The decline in male fertility is an emerging problem in modern societies. The increasing trend for couples to have children at a later age, along with unhealthy lifestyles, and detrimental environmental factors are reducing the general fertility rates. According to the World Health Organization (WHO), infertility can be defined as a disease from the reproductive system that prevents a couple from conceiving, after 12 months of regular and unprotected sexual activity. This health issue affects approximately $15 \%$ of couples worldwide and is thought that the male factor is associated with around half of these cases [1]. Multiple causes affect male reproductive potential. However, about $30-50 \%$ of cases of male infertility have unexplained causes and are classified as idiopathic. Recently, it has been proposed that idiopathic infertility could be explained by the presence of high levels of reactive oxygen species (ROS) [2]. In fact, evidence suggests that ROS-mediated damage contributes to about $30-80 \%$ of male infertility cases [3].

In normal physiological conditions, reactive oxygen species (ROS) and antioxidants balance each other, which is essential for the maintenance of several molecular signalling pathways. However, when ROS exceeds the antioxidant capacity, the cell turns into a state of oxidative stress (OS). Prolonged exposure to OS is extremely prejudicial to cellular systems, promoting the disruption of signalling pathways, affecting essential metabolic processes, resulting in the degradation of cellular machinery [4]. The male reproductive system is very sensitive to OS. Spermatozoa are cells especially vulnerable to ROS-attack due to the abundance of polyunsaturated fatty acids (PUFAs) in their plasma membrane. PUFAs are essential for plasma membrane fluidity, which is essential for zona pellucida binding and the process of fertilization [5]. Furthermore, spermatozoa are known to carry a very limited amount of cytoplasm, which results in a lack of antioxidant defences, and inefficiency in repairing oxidative damage [6]. ROS are known for playing a dual role in biological systems, having prejudicial and beneficial effects. Evidence suggests that certain levels of ROS are required for physiological sperm functions, including sperm capacitation, hyperactivation, acrosomal reaction, and sperm-oocyte fusion [7-9]. On the other hand, in spermatozoa, the overproduction of ROS results in lipid peroxidation (LPO) of membranes [10], protein modification [11] DNA damage [12], and increased apoptosis. These pathological events have been negatively correlated with sperm motility [13], sperm morphology [14], and male fertility capacity [15].

Couples affected by infertility often choose to pursue parenthood through the help of assisted reproduction technology (ART). The implementation of ART allowed several infertile couples to achieve a successful pregnancy. However, the success rate of ART is still considered low, being at best $50.4 \%$, in < 35-year-old women with 3 good quality embryos, according to the 2011 study of Vernon, et al. [16]. ART is also known to increase the exposure of gametes and embryos to ROS. In the case of male gametes, the removal of seminal plasma, as well as sperm processing techniques (centrifugation, light exposure, temperature) causes 
an increase in ROS production and promotes a reduction in sperm quality [17], decreasing (even more) the chances of achieving a successful pregnancy [18]. To prevent the oxidative damage of spermatozoa during ART, the sperm preparation medium is often supplemented with antioxidants.

Hyperoside (quercetin 3-O- $\beta$-D-galactoside) (HYP) is a flavonol glycoside, commonly found in plants of the genera Hypericum [19] and Crataegus [20]. It is a product of quercetin glycosylation of the hydroxyl group on C-3, with a galactoside group [21]. HYP extraction and isolation are difficult, due to their low concentrations, and their synthesis is costly. Nevertheless, this phytochemical has gained popularity due to its anti-cancer [22], antiinflammatory [23], anti-thrombotic [24], and anti-depressant [25] pharmacological properties. Recent studies have also explored the antioxidant effects of HYP. HYP was reported to possess cytoprotective properties against OS in lung fibroblast cells [26]. Also, it was reported that HYP protects granulosa cells against hydrogen peroxide $\left(\mathrm{H}_{2} \mathrm{O}_{2}\right)$-induced cell apoptosis and OS, revealing potential benefits on female reproductive capacity [27]. Biagi M. and colleagues reported that Castanea sativa Miller leaf extract, particularly rich in HYP, showed scavenging properties against OS in human sperm and showed being capable to protect sperm membranes and the acrosomes [28]. All these findings suggest that HYP can be used as a potential antioxidant in disorders associated with oxidative damage. On the other hand, VC (L-ascorbic acid) is a water-soluble vitamin known for its antioxidant properties. This micronutrient is a reducing agent and acts like an electron donor that reacts with substrates such as $\mathrm{H}_{2} \mathrm{O}_{2}$, generating ascorbyl radicals, a relatively stable free radical [29]. VC cannot be synthesized by human metabolism, meaning that its uptake comes straight from food [30]. Its concentration in the seminal fluid can be 10 times higher than in the serum, with values ranging between 200-700 $\mu \mathrm{M}$ [31-35]. VC is commonly prescribed in oral antioxidant therapies for infertile men (usually in combination with other compounds), and it is reported to decrease sperm DNA fragmentation and improve sperm-quality parameters [36-39]. In vitro studies did also report that the supplementation of sperm medium with VC was able to decrease negative effects of vitrification on sperm parameters and chromatin quality [40], and improve DNA integrity [41, 42].

To our knowledge, no studies have been performed regarding the potential of HYP supplementation of the sperm preservation medium used during ART. Thus, we propose to test and compare the efficacy of sperm preservation media supplementation with HYP and VC in the prevention of spermatozoa-oxidative damage. To test the sperm-protective potential of these compounds, we supplemented Ham's F12 medium with VC $(600 \mu \mathrm{M})$ and HYP $(100$ and $500 \mu \mathrm{M})$ and maintained spermatozoa for one hour at $37^{\circ} \mathrm{C}$. Sperm motility and vitality, were evaluated before and after treatment. Subsequently, protein and lipid oxidative damage, DNA fragmentation, and mitochondrial membrane potential (MMP) of spermatozoa were assessed. The total antioxidant capacity (TAC) of the treatment media was also evaluated, and the spermatozoa metabolic profile was investigated.

\section{Materials and Methods}

\section{Patient characterization and study design}

Human sperm samples were collected from Centro de Genética da Reprodução Professor Alberto Barros, located in Porto, Portugal, after approval by the Joint Ethics Committee CHUP/ICBAS (2021/CE/P002 [P342/ CETI/ICBAS]) during November 2020 and June 2021. The semen samples were provided by male patients of reproductive age undergoing fertility assessment, after 2-4 days of abstinence. Semen samples were obtained by masturbation and placed in sterile tubes. Patients with inflammatory diseases, cancer, or other health conditions that may severely affect their fertility potential were discarded. Also, patients were asked to provide information on the consumption of tobacco, alcohol, and other substances that could interfere with the experiment. All patients included in this study signed informed written consent. Sperm samples were characterized according to the WHO guidelines for laboratory examination and processing of human sperm [43]. Only samples having the following normal semen parameters, according to the WHO-criteria, 


\section{Cellular Physiology Cell Physiol Biochem 2022;56(S1):1-23 \\ \begin{tabular}{ll|l} 
and Biochemistry & $\begin{array}{l}\text { DOl: } 10.33594 / 000000487 \\
\text { Published online: } 8 \text { January } 2022\end{array}$ & $\begin{array}{l}\text { C } 2022 \text { The Author(s). Published by } \\
\text { Cell Physiol Biochem Press GmbH\&Co. KG }\end{array}$
\end{tabular} \\ Moreira et al.: Vitamin $\mathrm{C}$ and Hyperoside Protect Human Spermatozoa}

were used in this project: sperm concentration $\geq 15$ million $/ \mathrm{mL}$, total sperm motility $\geq 40 \%$, and sperm vitality $\geq 58 \%$. The fresh semen samples were centrifuged at $500 \mathrm{~g}$ for 5 minutes at room temperature. The seminal fluid was discarded, and the pellet was washed with $1 \mathrm{~mL}$ of phosphate-buffered saline (PBS) solution. After another centrifugation at $500 \mathrm{~g}$ for 5 minutes, the supernatant was discarded, and the pellet was resuspended in Ham F12 medium.

To test if HYP (HWI group, Rülzheim, Germany) had a cytotoxic effect in human spermatozoa, sperm samples (10 million sperm/condition) were incubated with increasing concentrations of HYP $(0,5,50,100$, and $500 \mu \mathrm{M}$ ), for $1 \mathrm{~h}$ at $37^{\circ} \mathrm{C}, 5 \% \mathrm{CO}_{2}$. Sperm vitality and sperm motility were measured before and after the experiment. The concentrations of 100 and $500 \mu \mathrm{M}$ of HYP (1h of incubation time) were selected for further experiments. To test the sperm-protective potential of HYP and VC (Sigma-Aldrich, St. Louis, Missouri, USA), 10 million spermatozoa were incubated for $1 \mathrm{~h}$ at $37^{\circ} \mathrm{C}, 5 \% \mathrm{CO}_{2}$ in the following conditions: 1) Ham F12 medium; 2) Ham F12 medium + $600 \mu \mathrm{M}$ VC; 3) Ham F12 medium + $100 \mu \mathrm{M}$ HYP; 4) Ham F12 medium + $500 \mu \mathrm{M}$ HYP; 5) Ham F12 medium $+300 \mu \mathrm{M} \mathrm{H}_{2} \mathrm{O}_{2}$; 6) Ham F12 medium + $600 \mu \mathrm{M} \mathrm{VC}+300 \mu \mathrm{M} \mathrm{H}_{2} \mathrm{O}_{2}$; 7) Ham F12 medium + $100 \mu \mathrm{M} \mathrm{HYP}+300 \mu \mathrm{M} \mathrm{H}_{2} \mathrm{O}_{2}$; 8) Ham F12 medium + $500 \mu \mathrm{M} \mathrm{HYP}+300 \mu \mathrm{M} \mathrm{H}_{2} \mathrm{O}_{2}$. $\mathrm{H}_{2} \mathrm{O}_{2}$ (LabChem, Lisbon, Portugal) was used as a positive control for OS, as described in [44, 45]. VC concentration of $600 \mu \mathrm{M}$ was chosen according to [31-35]. Sperm vitality and sperm motility were assessed before and after the experiment according to the WHO guidelines [43]. Afterwards, samples were centrifuged at $500 \mathrm{~g}$, $37^{\circ} \mathrm{C}$. Sperm pellets and post-treatment media were stored at $-80^{\circ} \mathrm{C}$ until used in further analysis.

\section{Oxidative stress evaluation}

Sperm pellets were resuspended in $10 \mu \mathrm{L}$ of $1 \%$ SDS lysis buffer $\left(1 \mu \mathrm{L}\right.$ for every $10^{6}$ cells). The samples were vortex and left at room temperature for $60 \mathrm{~min}$ to promote the lysis reaction. Subsequently, lysates were centrifuged at $14000 \mathrm{~g}$ for 20 minutes, at room temperature. The cell debris pellet was discarded. Protein quantification was performed using the Pierce Bicinchoninic acid protein assay (Thermo Fisher Scientific, Massachusetts, USA). Levels of lipid peroxidation, protein carbonylation, and protein nitration were evaluated by immunoblotting. For lipid peroxidation and protein nitration levels detection, $5 \mu \mathrm{g}$ of protein was diluted in PBS to a final volume of $100 \mu \mathrm{L}$ and transferred to polyvinylidene difluoride (PVDF) membranes through a slot-blot system. For protein carbonylation evaluation, we used the protocol described in [46]. In resume, $5 \mu \mathrm{g}$ of protein was diluted in PBS to a final volume of $20 \mu \mathrm{L}$. To each sample was added $20 \mu \mathrm{L}$ of $12 \%$ SDS solution for protein denaturation and carbonyl groups exposer. Subsequently, $40 \mu \mathrm{L}$ of 20 mM 2,4-dinitrophenylhydrazine (DNPH) in 10\% trifluoroacetic acid (TFA) was added, and the reaction was allowed to occur for $30 \mathrm{~min}$ at room temperature, in the dark. To stop the reaction between carbonyl groups and DNPH, $30 \mu \mathrm{L}$ of $2 \mathrm{M}$ Tris with $18 \% \beta$-mercaptoethanol solution was added. $2.4 \mu \mathrm{L}$ of the derivatized samples were diluted in 107.6 $\mu \mathrm{L}$ of PBS and transferred to PVDF membranes through a slot-blot system.

Membranes were then blocked with a blocking solution [5\% bovine serum albumin (BSA) in TrisBuffered Saline, $0.1 \%$ Tween 20 (TBS-T)] for $1 \mathrm{~h} 30$ and incubated overnight with the correspondent primary antibody. For lipid peroxidation evaluation, the primary antibody used was anti-4-hydroxynonenal (4HNE) (1:1000 diluted in 1\% BSA TBS-T; AB5605, EMD Millipore, Temecula, CA, USA). For protein nitration evaluation, the primary antibody used was anti-3-nitrotyrosine (NT) (1:1000 diluted in 1\% BSA TBS-T; 9691S, Cell Signaling Technology, Danvers, MA, USA). For protein carbonylation evaluation, the primary antibody used was anti-dinitrophenol (DNP) (1:5000 diluted in 1\% BSA TBS-T; D9656, Sigma-Aldrich, St. Louis, Missouri, USA). Membranes were washed with TBS-T and incubated with an appropriate secondary antibody for $1 \mathrm{~h} 30$ [Anti-Goat 1:5000 diluted in 1\% BSA TBS-T (A4187) or Anti-Rabbit 1:5000 diluted in 1\% BSA TBS-T (A3687), both from Sigma-Aldrich, St. Louis, Missouri, USA]. Immuno-reactive proteins were detected through reaction with an ECF substrate (GE Healthcare, Buckinghamshire, UK), and analyzed by ChemiDoc $^{\mathrm{TM}}$ MP Imaging system (Bio-Rad, California, USA). Total protein was assessed and quantified by Ponceau staining. Results were normalized to total protein.

\section{Post-treatment media total antioxidant capacity}

The TAC of the post-treatment media samples was measured by Ferric Reducing Antioxidant Power (FRAP) assay as described in [47]. FRAP reagent was freshly prepared by mixing $300 \mathrm{mM}$ acetate buffer (pH 3.6), $10 \mathrm{mM} \mathrm{2,4,6-tripyridyl-S-triazine} \mathrm{(TPTZ)} \mathrm{in} 40 \mathrm{mM} \mathrm{HCl}$ and $20 \mathrm{mM} \mathrm{FeCl}_{3} \cdot 6 \mathrm{H}_{2} \mathrm{O}$ in the ratio of 10:1:1.

Briefly, in a 96-well plate, $6 \mu \mathrm{L}$ of post-treatment media samples were added to $180 \mu \mathrm{L}$ of FRAP reagent. Triplicates were made for each sample. Distilled water $\left(\mathrm{dH}_{2} \mathrm{O}\right)$ was used as negative control and VC $(1000 \mu \mathrm{M})$ 


\section{Cellular Physiology Cell Physiol Biochem 2022;56(S1):1-23

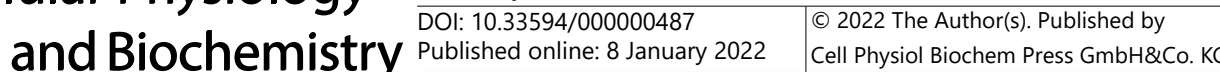 \\ Moreira et al.: Vitamin $\mathrm{C}$ and Hyperoside Protect Human Spermatozoa}

was used as an antioxidant standard. Both controls were treated in the same way as media samples. The absorbance was read at $593 \mathrm{~nm}$, immediately after the addition of the FRAP reagent ( $0 \mathrm{~min}$ ) and after 40 min. Between measurements, the plate was kept in the dark, at room temperature. The antioxidant potential of the samples was determined against VC $(1000 \mu \mathrm{M})$ standard and corrected using the absorbance value of $\mathrm{dH}_{2} \mathrm{O}$ absorbance. FRAP value ( $\mu \mathrm{mol}$ antioxidant potential/L) was calculated using the formula described in [47].

\section{Sperm DNA fragmentation evaluation}

The evaluation of sperm DNA fragmentation was performed by the terminal deoxynucleotidyl transferase dUTP Nick End Labeling (TUNEL) assay, using in-situ Cell Death Detection Kit (Fluorescein) from Roche Diagnostics GmbH (Mannheim, Germany). Spermatozoa (10 million) were collected and treated with HYP, and VC as previously described. A smear of each sample was performed on adhesive slides. The slides were subsequently fixed with $4 \%$ paraformaldehyde, for $1 \mathrm{~h}$ at room temperature and then rinsed with PBS. For cell permeabilization, slides were immersed in a solution of $0.1 \%$ sodium citrate containing $0.1 \%$ Triton $\mathrm{X}$, for $2 \mathrm{~min}$ at $4^{\circ} \mathrm{C}$. After two washes with PBS for $5 \mathrm{~min}, 50 \mu \mathrm{L}$ of the TUNEL reaction mix [5 $\mu \mathrm{L}$ of terminal deoxynucleotidyl transferase (TdT) and $45 \mu \mathrm{L}$ of labeled deoxyuridine triphosphate nucleotides (dUTPs) mixture] was added to each slide. A coverslip was placed to prevent evaporation. The slides were incubated in a humidified chamber at $37^{\circ} \mathrm{C}$ for $1 \mathrm{~h}$, in darkness. The slides were then washed four times with PBS ( 2 min each). Subsequently, coverslips were mounted using mounting medium VECTASHELD (30 Ingold Road, Burlingame, CA 94010, USA). The results were visualized in a Nikon Eclipse E400 microscope equipped with a Y-FL epi-fluorescence attachment and HB-10103AF Super high-pressure mercury lamp power supply (Nikon, Shinagawa, Tokyo, Japan), coupled with a Nikon NIS Elements Image Software. 200 spermatozoa were counted on each slide. The total number of spermatozoa was quantified under blue fluorescence (corresponding to the DAPI staining of the nucleus). Spermatozoa presenting DNA fragmentation also present green fluorescence (corresponding to the dUTPs inserted in the DNA breaks by TdT). The percentage of DNA fragmentation was calculated.

\section{Mitochondrial membrane potential evaluation}

The MMP of spermatozoa was measured by using the lipophilic probe 5-5',6-6'-tetrachloro-1,1',3,3'tetraethylbenzimidazolcarbocyanine iodide (JC-1) (T3168, Invitrogen ${ }^{\mathrm{TM}}$, Carlsbad, CA, USA), which can selectively penetrate mitochondria [45]. In spermatozoa with damaged mitochondrial membrane, the JC-1 remains in the cytoplasm, in a monomeric form. Meanwhile, in spermatozoa with normal mitochondrial membranes occur the accumulation of JC- 1 in the membrane, promoting the formation of JC-1 aggregates. Briefly, 1 million spermatozoa were collected after treatment, washed with PBS $(500 \mathrm{~g}, 5 \mathrm{~min})$ and incubated with JC-1 (1 $\mathrm{\mu g} / \mathrm{mL}$ in PBS) for $30 \mathrm{~min}$ at $37^{\circ} \mathrm{C}$. As a positive control, spermatozoa were incubated with a $20 \%$ DMSO solution to promote the increase of mitochondrial membrane potential. After the incubation period, spermatozoa were washed with PBS ( $500 \mathrm{~g}, 5 \mathrm{~min})$ two times. Pellets were resuspended in $750 \mu \mathrm{L}$ of PBS and transferred to 96-well plates (performed in triplicate). The fluorescence of the JC-1 monomers (ex 485/530 nm; excitation/emission) and JC-1 aggregates (535/590 nm; excitation/emission) were assessed by a Synergy ${ }^{\mathrm{TM}} \mathrm{H} 1$ multi-mode microplate reader (BioTek, Winooski, VT, USA). The ratio between JC-1 aggregates/monomers was calculated and used as an MMP marker.

\section{Post-treatment media metabolite analysis}

Metabolites present in the post-treatment media were assessed by proton nuclear magnetic resonance $\left({ }^{1} \mathrm{H}-\mathrm{NMR}\right)$ and spectra analysis. 1D ${ }^{1} \mathrm{H}-\mathrm{NMR}$ spectra were acquired on a $500 \mathrm{MHz}$ Bruker Avance III HD spectrometer equipped with a 5-mm TXI probe, at 298K. To each post-treatment medium $(180 \mu \mathrm{L})$ it was added $45 \mu \mathrm{L}$ of sodium fumarate (final concentration $=2 \mathrm{mM}$ ), for a final sample volume of $225 \mu \mathrm{L}$. Sodium fumarate was used as an internal reference for metabolite quantification in the media. The quantified metabolites were the following (multiplicity, chemical shift(ppm)): pyruvate (singlet, 2.37), acetate (singlet, 1.90), lactate (doublet, 1.32), alanine (doublet, 1.47), and malate (double doublet, 2.65). The spectra were manually phased, and baseline corrected. NUTS-Pro ${ }^{\mathrm{TM}}$ NMR software (Acorn NMR, Inc, Fremont, CA, USA) was used to integrate the chosen metabolite peaks. The concentration of the metabolites is expressed as nmol $/ 10^{6}$ sperm cells. 


\section{Statistical Analysis}

All data presented are expressed as whisker boxes (median, $25^{\text {th }}$ to $75^{\text {th }}$ percentiles \pm minimum and maximum values). Variations between groups regarding sperm total motility, sperm vitality, OS biomarkers, DNA fragmentation, MMP, and metabolite quantification were evaluated by one-way ANOVA followed by the correction for multiple comparisons by controlling the False Discovery Rate (FDR). The two-stage step-up method of Benjamini, Krieger, and Yekutieli was the test used to assess multiple comparisons. Fold variation to the $0 \mu \mathrm{M}$ group was calculated for OS biomarkers quantification, DNA fragmentation evaluation, and MMP assessment. The differences between the groups in the cytotoxic test and the TAC media assessment were performed using one-way ANOVA, followed by Tukey's post hoc test for multiple comparisons. Values of $\mathrm{P}<$ 0.05 were considered statistically different. The statistical analysis of this work was performed by GraphPad Prism 8 software (GraphPad Software Inc., San Diego, CA, USA).

\section{Results}

Supplementation of sperm preservation media with hyperoside has no cytotoxic effects on human sperm

After treating human spermatozoa with increasing doses of HYP (in $\mu \mathrm{M}: 0,5,50,100$, and 500), for $1 \mathrm{~h}$ at $37^{\circ} \mathrm{C}$, cytotoxicity was evaluated as in [48, 49], through assessment of sperm motility and vitality. Fig. 1 represents sperm total motility and sperm vitality, after preservation in media supplemented with HYP. Regarding sperm motility, we could not find any significant differences between the HYP treated groups (in $\mu \mathrm{M}: 5,50,100$, and $500)$, and the control group $(0 \mu \mathrm{M})($ Fig. 1A). Similarly, we could not find any significant differences in spermatozoa vitality after preservation in media supplemented with HYP at any concentration, and the control group (Fig. 1B). No cytotoxic effects were found in sperm samples preserved in media supplemented with any of the tested HYP concentrations. The concentrations of 100 and $500 \mu \mathrm{M}$ of HYP were selected for further testing.

Supplementation of sperm preservation media with vitamin $C$ and hyperoside preserves sperm motility under oxidative stress conditions

To test the cytoprotective effects of VC and HYP supplementation in human spermatozoa the following concentration were selected: $600 \mu \mathrm{M}$ for VC [31-35]; 100 and $500 \mu \mathrm{M}$ for HYP (after considering the previous cytotoxicity test results), $1 \mathrm{~h}$ at $37^{\circ} \mathrm{C} . \mathrm{H}_{2} \mathrm{O}_{2}(300 \mu \mathrm{M})$ was used as an OS-inducer in spermatozoa. Fig. 2 represents spermatozoa total motility and
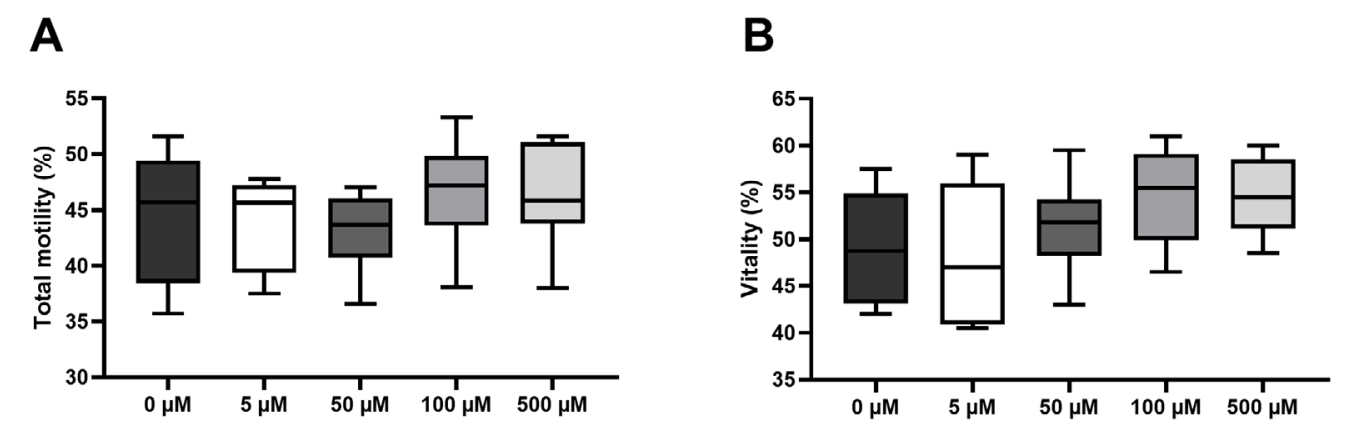

Fig. 1. Evaluation of hyperoside (HYP) cytotoxicity for human spermatozoa. (A) represents the percentage of sperm total motility $(\mathrm{N}=6)$ after supplementation with increasing doses of HYP. (B) represents the percentage of sperm vitality $(\mathrm{N}=6)$ after supplementation with increasing doses of HYP. Results are represented as Tukey's whisker boxes (median, $25^{\text {th }}$ to $75^{\text {th }}$ percentiles \pm minimum and maximum values). No statistical differences were found between groups (one-way ANOVA followed Tukey post hoc test for multiple comparisons). 


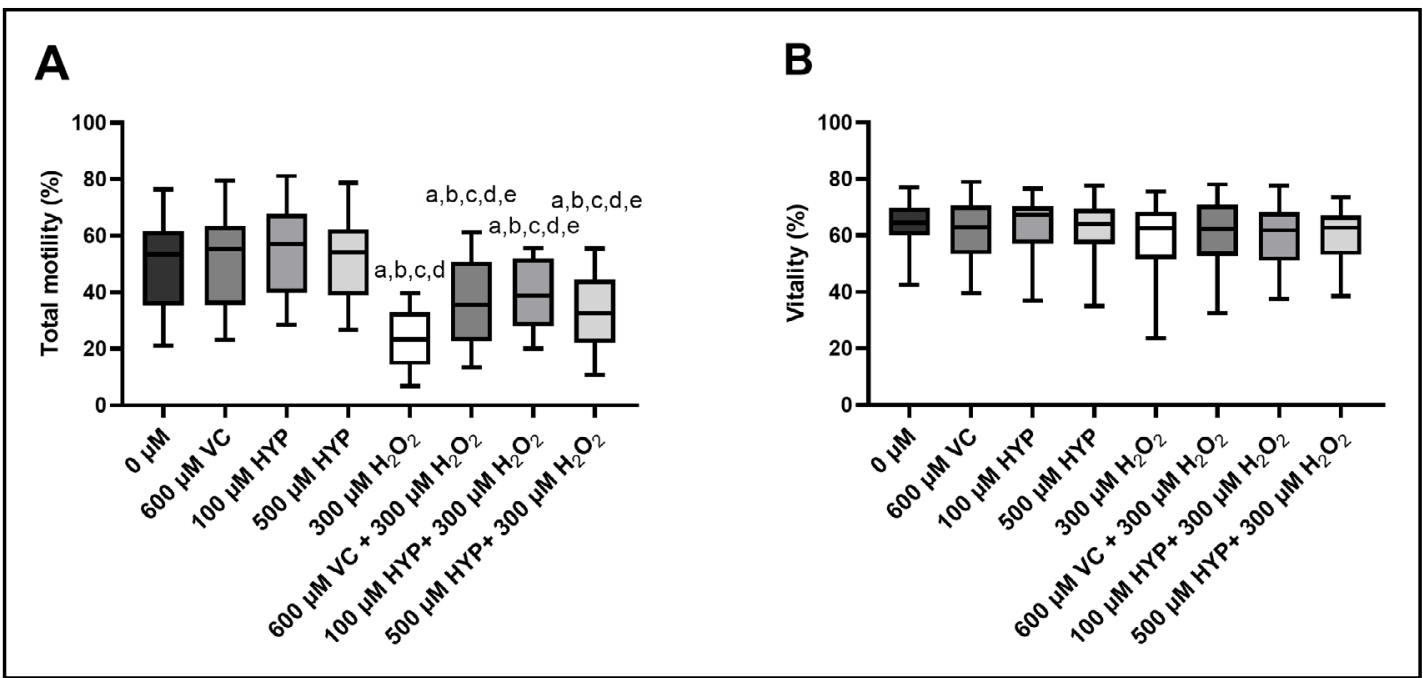

Fig. 2. Evaluation of the cytoprotective effects of vitamin C (VC) and hyperoside (HYP) sperm media supplementation under oxidative stress conditions. (A) represents the variations in the percentage of total sperm motility $(\mathrm{N}=20)$ after $1 \mathrm{~h}$ treatment with VC $(600 \mu \mathrm{M})$, and HYP $(100$ and $500 \mu \mathrm{M})$ in the presence and absence of $\mathrm{H}_{2} \mathrm{O}_{2}(300 \mu \mathrm{M})$, herein used as an OS inducer. (B) represents the variations in the percentage of sperm vitality under the same conditions $(\mathrm{N}=20)$. Results are represented as whisker boxes (median, $25^{\text {th }}$ to $75^{\text {th }}$ percentiles \pm minimum and maximum values). Significantly different results (one-way ANOVA followed by the correction for multiple comparisons by controlling FDR, two-stage step-up method of Benjamini, Krieger, and Yekutieli; $\mathrm{p}<0.05$ ) are indicated as (a) relative to control; (b) relative to $600 \mu \mathrm{M}$ VC group; (c) relative to $100 \mu \mathrm{M}$ HYP group; (d) relative to $500 \mu \mathrm{M}$ HYP group; (e) relative to $300 \mu \mathrm{M} \mathrm{H}_{2} \mathrm{O}_{2}$ group.

spermatozoa vitality, after preservation in media supplemented with VC and HYP, in the presence and absence of $\mathrm{H}_{2} \mathrm{O}_{2}$. We found no differences regarding spermatozoa total motility after preservation in media supplemented with VC or HYP, in comparison with the control group $(0 \mu \mathrm{M})$, illustrating that supplementation of media with these antioxidants does not affect spermatozoa motility (Fig. 2A). However, spermatozoa motility decreased in the group exposed to $\mathrm{H}_{2} \mathrm{O}_{2}(300 \mu \mathrm{M})(22 \pm 10 \%)$ in comparison to the control group $(50 \pm 15 \%)$ and those preserved in media supplemented with VC and HYP $(100$ and $500 \mu \mathrm{M})(52 \pm 16 \%$; $55 \pm 15 \%$ and $51 \pm 14 \%$, respectively) suggesting that spermatozoa are under stress (Fig. $2 \mathrm{~A}$ ). The spermatozoa motility of the group preserved in the media supplemented with VC and treated with $\mathrm{H}_{2} \mathrm{O}_{2}(36 \pm 15 \%)$ was higher than in the group treated with $\mathrm{H}_{2} \mathrm{O}_{2}$ alone suggesting a cytoprotective effect of VC supplementation against the damage promoted by $\mathrm{H}_{2} \mathrm{O}_{2}$. Nevertheless, the spermatozoa motility of this group was decreased in comparison to the control group and the only-antioxidant groups. The motility of the groups preserved in media supplemented with HYP $(100$ and $500 \mu \mathrm{M})$ and treated with $\mathrm{H}_{2} \mathrm{O}_{2}(39 \pm 12 \%$ and $35 \pm$ $13 \%$, respectively) was higher than the motility of the group treated only with $\mathrm{H}_{2} \mathrm{O}_{2}$. Still, the spermatozoa motility of those groups decreased when compared to the control group and the only-antioxidant groups. These results suggest a protective effect of the antioxidants VC and HYP under OS conditions.

Regarding spermatozoa vitality, none of the preservation media supplemented with VC and HYP (100 and $500 \mu \mathrm{M})$ with or without $\mathrm{H}_{2} \mathrm{O}_{2}$ promoted a decrease of spermatozoa vitality after $1 \mathrm{~h}$ treatment (Fig. 2B). These results suggest that, although the concentration of $300 \mu \mathrm{M}$ of $\mathrm{H}_{2} \mathrm{O}_{2}$ can induce a decrease in sperm motility, this treatment does not affect sperm vitality. 
Supplementation of sperm preservation media with hyperoside increases the total antioxidant capacity of the media

After preserving spermatozoa with media supplemented with HYP $(100$ and $500 \mu \mathrm{M})$ in the presence and absence of $\mathrm{H}_{2} \mathrm{O}_{2}$ for $1 \mathrm{~h}$ at $37^{\circ} \mathrm{C}$, TAC of the media was measured by FRAP. Fig. 3A represents the TAC levels of the media, herein measured by FRAP levels. VC was used as a standard for antioxidant capacity, and, because of that, TAC of the sperm preservation media supplemented with VC $(600 \mu \mathrm{M})$ was not assessed. Nevertheless, VC $(1000 \mu \mathrm{M})$ was used as a standard value of TAC $(2 \mu \mathrm{mol}$ antioxidant capacity/L). The media containing $500 \mu \mathrm{M}$ of HYP (in the presence and absence of $\mathrm{H}_{2} \mathrm{O}_{2}$ ) presented the highest TAC levels (4.78 \pm 0.73 and $4.54 \pm 0.58 \mu \mathrm{mol}$ antioxidant capacity/L, respectively). Also, the TAC value of the spermatozoa preservation media supplemented with $500 \mu \mathrm{M}$ of HYP was higher than the standard TAC level of VC $(1000 \mu \mathrm{M})$. The media containing $100 \mu \mathrm{M}$ of HYP (in the presence and absence of $\left.\mathrm{H}_{2} \mathrm{O}_{2}\right)$ also presented higher TAC levels $(1.22 \pm 0.31$ and $1.15 \pm 0.24$ $\mu \mathrm{mol}$ antioxidant capacity/L, respectively $)$ in comparison to the control $(0.21 \pm 0.06 \mu \mathrm{mol}$ antioxidant capacity/L) and only- $\mathrm{H}_{2} \mathrm{O}_{2}$ group $(0.18 \pm 0.06 \mu \mathrm{mol}$ antioxidant capacity/L). Although the TAC of these media was lower than the ones containing $500 \mu \mathrm{M}$ of HYP. Additionally, the TAC of the spermatozoa preservation media supplemented with $100 \mu \mathrm{M}$ of HYP was lower than the standard TAC level of VC $(1000 \mu \mathrm{M})$. The medium containing $\mathrm{H}_{2} \mathrm{O}_{2}(300 \mu \mathrm{M})$ had the lowest TAC from all the media tested. However, no difference was found regarding the TAC from this group and the TAC from the control group $(0 \mu \mathrm{M})$. Notwithstanding, the FRAP does not react with $\mathrm{H}_{2} \mathrm{O}_{2}$, which can justify the absence of differences concerning the groups with the presence of $\mathrm{H}_{2} \mathrm{O}_{2}$ [50]. The FRAP assay measures the ability of an antioxidant compound to reduce ferric ions $\left(\mathrm{Fe}^{3+}\right)$ to ferrous ions $\left(\mathrm{Fe}^{2+}\right)$ and this reaction is linked to a colour change (absorbance at $593 \mathrm{~nm}$ ) [47].

Supplementation of sperm preservation media with vitamin $C$ and hyperoside appears to protect human sperm against lipid peroxidation under oxidative stress conditions

Elevated levels of $\mathrm{H}_{2} \mathrm{O}_{2}$ are known to promote OS and cause several damages to spermatozoa biomolecules, such as lipids and proteins. OS biomarkers were quantified to evaluate the oxidative damage promoted by $\mathrm{H}_{2} \mathrm{O}_{2}$ in human sperm and to further test the cytoprotective effects of sperm preservation media supplementation with VC and HYP. Fig. 3 (panels B, C, and D) represents the levels of lipid peroxidation, protein carbonylation, and protein nitration found in human sperm after supplementation of sperm preservation media with VC and HYP in the presence and absence of $\mathrm{H}_{2} \mathrm{O}_{2}, 1 \mathrm{~h}, 37^{\circ} \mathrm{C}$.

Lipid peroxidation was assessed by the quantification of 4-HNE levels (Fig. 3B). Lipid peroxidation levels of the groups preserved in media supplemented with VC and HYP (100 and $500 \mu \mathrm{M})(1.25 \pm 0.54 ; 1.04 \pm 0.31$ and $1.04 \pm 0.45$ fold, respectively) and the control group (represented as a dashed line, treatment with no $\mathrm{HYP}$, no $\mathrm{VC}$, and no $\mathrm{H}_{2} \mathrm{O}_{2}$ ) were similar, after $1 \mathrm{~h}$ treatment. Meanwhile, in the group treated with only $\mathrm{H}_{2} \mathrm{O}_{2}(300 \mu \mathrm{M})(1.71 \pm$ 0.70 fold) the spermatozoa lipid peroxidation levels increased when compared to the control group and those preserved in media supplemented with HYP (100 and $500 \mu \mathrm{M})$ groups. The peroxidation levels of spermatozoa preserved in media supplemented with VC and HYP $(100$ and $500 \mu \mathrm{M})$, in the presence of $\mathrm{H}_{2} \mathrm{O}_{2}(1.39 \pm 0.61 ; 1.23 \pm 0.58$ and $1.30 \pm 0.57$ fold, respectively) were not significantly different from the levels detected in spermatozoa from the group treated with $\mathrm{H}_{2} \mathrm{O}_{2}$ alone (Fig. 3B). Notwithstanding, spermatozoa peroxidation levels in those groups tend to be lower in comparison to the levels detected in spermatozoa subjected only to $\mathrm{H}_{2} \mathrm{O}_{2}$, suggesting that cytoprotective action of VC and HYP may be occurring to some extent.

The DNP was used to assess protein carbonylation levels induced by our treatments in spermatozoa (Fig. 3C). No statistical differences were found regarding the carbonylation levels of spermatozoa preserved in media supplemented with VC and HYP $(100$ and $500 \mu \mathrm{M})$ in the presence and absence of $\mathrm{H}_{2} \mathrm{O}_{2}$ in comparison to the control group. Further, no statistical difference was found regarding spermatozoa carbonylation levels after treatment with $\mathrm{H}_{2} \mathrm{O}_{2}$ alone, and the control group (Fig. 3C). Similar results were found regarding spermatozoa 
protein nitration levels, evaluated by the quantification of NT (Fig. 3D). No statistical differences were found regarding the nitration levels of spermatozoa preserved in media supplemented with VC and HYP $(100$ and $500 \mu \mathrm{M})$ in the presence and absence of $\mathrm{H}_{2} \mathrm{O}_{2}$ in comparison to the control group. Similarly, no statistical differences were found regarding the nitration levels of the groups treated with $\mathrm{H}_{2} \mathrm{O}_{2}(300 \mu \mathrm{M})$, and the control group (Fig. 3D).

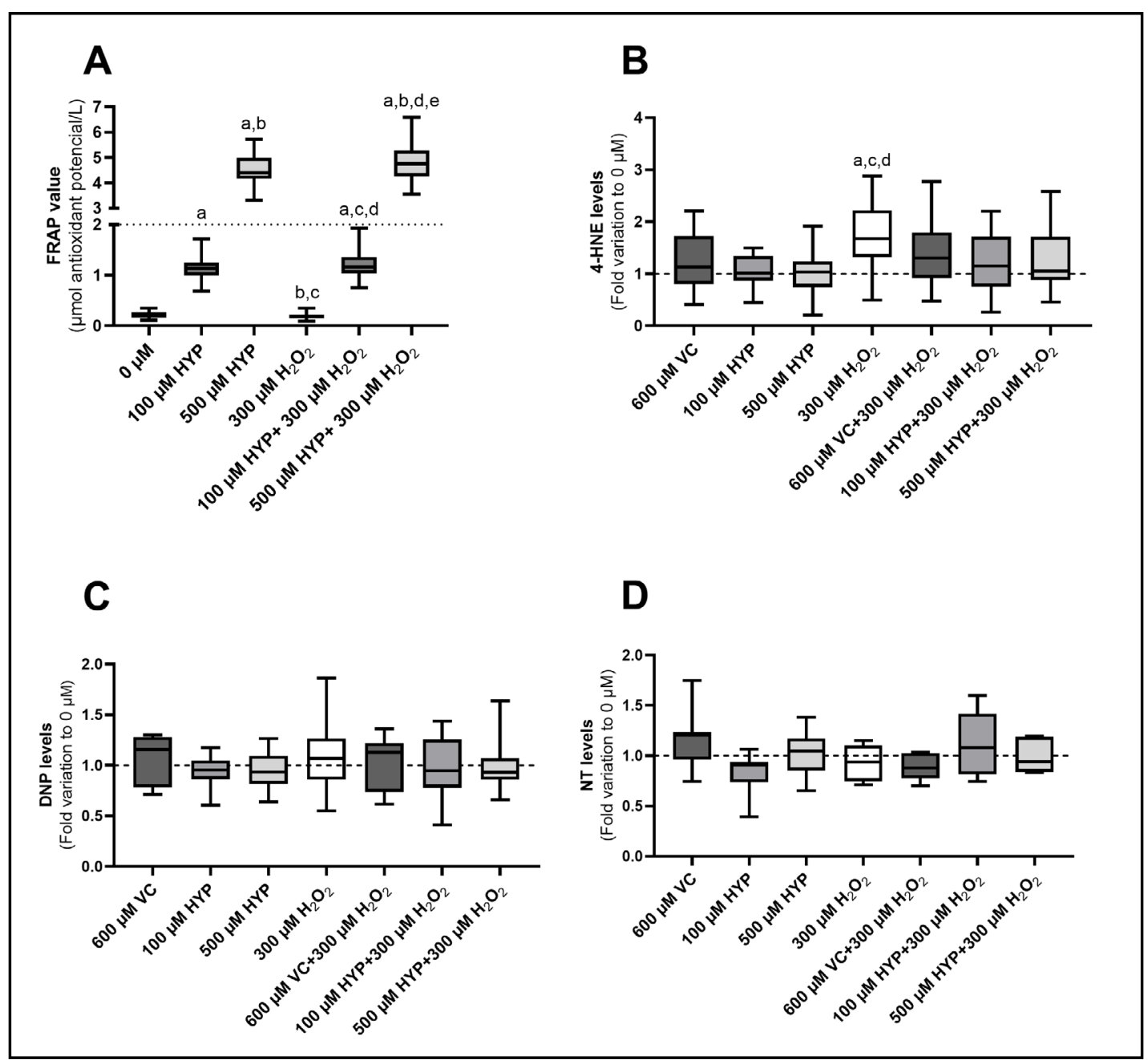

Fig. 3. Effects of vitamin C (VC) and hyperoside (HYP) media supplementation, under oxidative stress conditions, in the total antioxidant capacity (TAC) of the media and quantification of oxidative stress biomarkers in preserved spermatozoa. (A) represents the antioxidant capacity of media $(\mathrm{N}=20)$. Significantly different results (one-way ANOVA followed Tukey post hoc test for multiple comparisons; $\mathrm{p}<0.05$ ) are indicated as (a) relative to control; (b) relative to $100 \mu \mathrm{M}$ HYP group; (c) relative to $500 \mu \mathrm{M}$ HYP group; (d) relative to $300 \mu \mathrm{M} \mathrm{H}_{2} \mathrm{O}_{2}$ group; (e) relative to $100 \mu \mathrm{M} \mathrm{HYP}+300 \mu \mathrm{M} \mathrm{H}_{2} \mathrm{O}_{2}$ group. (B) represents the 4-HNE expression levels found in spermatozoa after $1 \mathrm{~h}$ treatment in media supplemented with VC $(600 \mu \mathrm{M})$, and HYP $(100$ and $500 \mu \mathrm{M})$ in the presence and absence of $\mathrm{H}_{2} \mathrm{O}_{2}(300 \mu \mathrm{M})$, herein used as an oxidative stress inducer $(\mathrm{N}=20)$. (C) represents DNP levels quantified after the reaction of DNPH with spermatozoa's protein carbonyl groups, after treatments $(\mathrm{N}=10)$. (D) represents the NT expression levels found in spermatozoa, after treatments $(\mathrm{N}=10)$. Fold variation was performed to the control group (Ham-F12 medium with no HYP, no VC, nor $\mathrm{H}_{2} \mathrm{O}_{2}$ ) represented as a dashed line. Significantly different results (one-way ANOVA followed by the correction for multiple comparisons by controlling FDR, two-stage step-up method of Benjamini, Krieger, and Yekutieli; $\mathrm{p}<0.05$ ) are indicated as (a) relative to control; (c) relative to $100 \mu \mathrm{M}$ HYP group; (d) relative to $500 \mu \mathrm{M}$ HYP group. All results are represented as Tukey's whisker boxes (median, $25^{\text {th }}$ to 75 th percentiles \pm minimum and maximum values). 


\section{Cellular Physiology Cell Physiol Biochem 2022;56(S1):1-23 \\ \begin{tabular}{ll|l} 
and & $\begin{array}{l}\text { DOl: 10.33594/000000487 } \\
\text { Published online: } 8 \text { January 2022 }\end{array}$ & $\begin{array}{l}\text { O } 2022 \text { The Author(s). Published by } \\
\text { Cell Physiol Biochem Press GmbH\&Co. KG }\end{array}$ \\
\cline { 2 - 3 }
\end{tabular} \\ Moreira et al.: Vitamin C and Hyperoside Protect Human Spermatozoa}

Supplementation of sperm preservation media with vitamin $C$ and hyperoside prevents DNA fragmentation in human spermatozoa under oxidative stress conditions

One of the consequences of a prolonged OS situation is DNA damage [12], and increased apoptosis. In spermatozoa, DNA damage is known to severely decrease the chances of achieving a successful pregnancy and increase the risk of abortion. To test if supplementation of sperm media with VC and HYP was able to prevent DNA fragmentation induced by OS we performed a TUNEL assay after preservation in the experimental conditions. Fig. 4A represents the result of the TUNEL assay visualized by fluorescence. Spermatozoa with DNA fragmentation present a green fluorescence corresponding to the dUTPs inserted in the DNA breaks. The nuclei were stained with DAPI, which has a blue fluorescence. The merge of the green/blue channels allows the detection of the percentage of sperm DNA fragmentation for each condition. Fig. 4B represents the percentage of DNA fragmentation detected in human spermatozoa after $1 \mathrm{~h}$ incubation in media supplemented with VC and HYP $(100 \mu \mathrm{M})$ in the presence and absence of $\mathrm{H}_{2} \mathrm{O}_{2}$. Our results showed no differences regarding sperm DNA fragmentation between the control group (represented as a dashed line, treatment with no HYP, no VC, and no $\left.\mathrm{H}_{2} \mathrm{O}_{2}\right)$, the VC $(600 \mu \mathrm{M})(0.88 \pm 0.08$-fold $)$ and the HYP $(100 \mu \mathrm{M})$ $(0.91 \pm 0.22$-fold $)$ supplemented groups. This indicates that the supplementation with VC $(600 \mu \mathrm{M})$ and HYP $(100 \mu \mathrm{M})$ does not induce DNA fragmentation per se. Spermatozoa treated with $\mathrm{H}_{2} \mathrm{O}_{2}(300 \mu \mathrm{M})$ had higher levels of DNA fragmentation by a $1.30 \pm 0.19$ fold variation to the control group. Furthermore, we found that spermatozoa supplemented with VC and HYP $(100 \mu \mathrm{M})$ in the presence of $\mathrm{H}_{2} \mathrm{O}_{2}(1.02 \pm 0.23$ and $1.02 \pm 0.20$ fold, respectively) exhibited lower levels of DNA fragmentation compared to the group treated only with $\mathrm{H}_{2} \mathrm{O}_{2}$. In addition, the DNA fragmentation levels of these groups did not differ from the control and antioxidants-only groups. These results may suggest that a cytoprotective effect against DNA damage could be promoted by the supplementation of VC and HYP in sperm preservation media.

Supplementation of sperm preservation media with vitamin $C$ and hyperoside cannot prevent alteration in the sperm mitochondrial membrane under oxidative stress conditions MMP is a strong indicator of mitochondrial functionality and can be used as a measure of electron transport chain (ETC) activity. Mitochondria are fundamental to producing cellular energy. In spermatozoa, several studies are reporting a positive correlation between MMP and motility. To test if media supplementation with VC and HYP can ensure mitochondrial activity, under conditions of OS, we used the JC-1 probe. Fig. 5 represents the ratio of JC-1-aggregates/monomers in human spermatozoa, after $1 \mathrm{~h}$ preservation in media supplemented with VC $(600 \mu \mathrm{M})$ and HYP $(100 \mu \mathrm{M})$ in the presence and absence of $\mathrm{H}_{2} \mathrm{O}_{2}$. Our results show no differences between the groups preserved in media supplemented with VC $(600 \mu \mathrm{M})(0.97 \pm 0.23$ fold $)$ and HYP $(100 \mu \mathrm{M})(0.92 \pm 0.19$ fold $)$ and the control group (represented as a dashed line, treatment with no HYP, no VC, and no $\mathrm{H}_{2} \mathrm{O}_{2}$ ), meaning that no MMP alterations were promoted by the antioxidant treatment, per se. A decrease in the MMP of spermatozoa can be observed in the group treated with $\mathrm{H}_{2} \mathrm{O}_{2}(300 \mu \mathrm{M})$ in comparison with the control group and with those preserved in media supplemented with antioxidants. However, no differences were found regarding spermatozoa MMP between the groups preserved in media supplemented with VC and HYP $(100 \mu \mathrm{M})$, in the presence of $\mathrm{H}_{2} \mathrm{O}_{2}, 0.72$ \pm 0.20 and $0.64 \pm 0.21$ fold, respectively), and the group treated with $\mathrm{H}_{2} \mathrm{O}_{2}$-only $(0.59 \pm 0.22$ fold). Also, following sperm motility results (Fig. 2A), the MMP of the groups preserved in media supplemented with antioxidants treated with $\mathrm{H}_{2} \mathrm{O}_{2}$ was decreased when compared to MMP of spermatozoa from the control and antioxidants-only groups. This suggests that the presence of VC $(600 \mu \mathrm{M})$ and HYP $(100 \mu \mathrm{M})$ in the sperm media is not able to prevent the decrease in the sperm MMP promoted by $\mathrm{H}_{2} \mathrm{O}_{2}$. 


\section{Cellular Physiology Cell Physiol Biochem 2022;56(S1):1-23 \begin{tabular}{ll|l} 
and Bol: 10.33594/000000487 & ( 2022 The Author(s). Published by \\
Cell Physiol Biochem Press GmbH\&Co. KG
\end{tabular} \\ Moreira et al.: Vitamin C and Hyperoside Protect Human Spermatozoa}

Fig. 4. Effects of vitamin C (VC) and hyperoside (HYP) media supplementation in spermatozoa DNA fragmentation under oxidative stress conditions. (A) represents the results of immunofluorescence staining of the spermatozoa DNA breaks by TUNEL (ex 480/535 nm; excitation/emission), and spermatozoa nuclei by DAPI (ex 395/460nm; excitation/emission). (B) represents the percentage of DNA fragmentation quantified in spermatozoa after $1 \mathrm{~h}$ treatment in media supplemented with VC $(600 \mu \mathrm{M})$, and HYP $(100 \mu \mathrm{M})$ in the presence and absence of $\mathrm{H}_{2} \mathrm{O}_{2}(300 \mu \mathrm{M})$, herein used as an oxidative stress inducer $(\mathrm{N}=10)$. Fold variation was performed to the control group (Ham-F12 medium with no $\mathrm{HYP}$, no VC, nor $\mathrm{H}_{2} \mathrm{O}_{2}$ ) represented as a dashed line. Results are represented as Tukey's whisker boxes (median, $25^{\text {th }}$ to $75^{\text {th }}$ percentiles \pm minimum and maximum values). Significantly different results (one-way ANOVA followed by the correction for multiple comparisons by controlling FDR, two-stage step-up method of Benjamini, Krieger, and Yekutieli; $\mathrm{p}<0.05$ ) are indicated as (a) relative to control; (b) relative to $600 \mu \mathrm{M}$ VC group; (c) relative to $100 \mu \mathrm{M}$ HYP group; (d) relative to $300 \mu \mathrm{M} \mathrm{H}_{2} \mathrm{O}_{2}$ group.

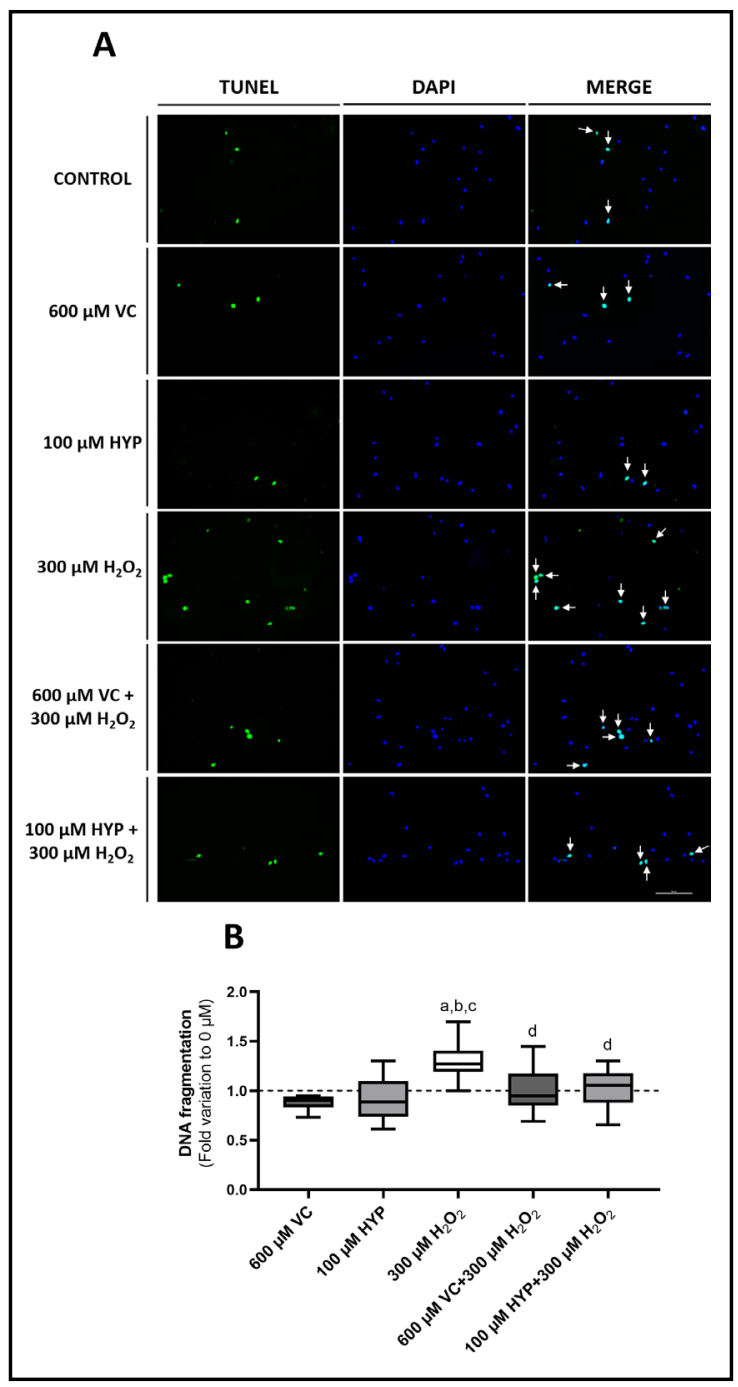

Fig. 5. Effects of vitamin C (VC) and hyperoside (HYP) media supplementation in mitochondria functionality of spermatozoa under oxidative stress conditions. Fold variation was performed to the control group (Ham-F12 medium with no HYP, no VC, nor $\mathrm{H}_{2} \mathrm{O}_{2}$ ) represented as a dashed line. Results are represented as Tukey's whisker boxes (median, $25^{\text {th }}$ to 75 th percentiles \pm minimum and maximum values). Significantly different results (oneway ANOVA followed by the correction for multiple comparisons by controlling FDR, two-stage step-up method of Benjamini, Krieger, and Yekutieli; $\mathrm{p}<0.05$ ) are indicated as (a) relative to control; (b) relative to $600 \mu \mathrm{M}$ VC group; (c) relative to $100 \mu \mathrm{M}$

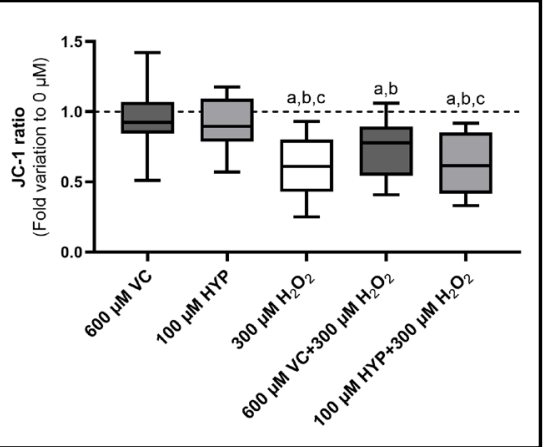
HYP group. 
Supplementation of sperm preservation media with vitamin $C$ and hyperoside cannot prevent alterations in the metabolism of spermatozoa under oxidative stress conditions

Metabolism is a network of biochemical reactions that ensure cell function. The study of spermatozoa metabolism can enlighten concerning what is going inside the cell. The effects of VC $(600 \mu \mathrm{M})$ and HYP $(100$ and $500 \mu \mathrm{M})$ supplementation, in the presence and absence of $\mathrm{H}_{2} \mathrm{O}_{2}$, on spermatozoa metabolism were assessed by ${ }^{1} \mathrm{H}-\mathrm{NMR}$ spectra analysis of the media. Fig. 6 represents the main metabolites identified in the studied groups: pyruvate (Fig. 6A); acetate (Fig. 6B); lactate (Fig. 6C); alanine (Fig. 6D) and malate (Fig. 6E).

Concerning pyruvate variation, no differences were observed in pyruvate variation in the media, between the control $\left(0.09 \pm 1.58 \mathrm{nmol} / 10^{6} \mathrm{cells}\right)$ and the ones supplemented with VC $(600 \mu \mathrm{M})$, and HYP $(100$ and $500 \mu \mathrm{M})(-0.23 \pm 1.92 ; 0.06 \pm 1.58$ and $0.65 \pm 1.48$ nmol $/ 10^{6}$ cells, respectively) (Fig. 6A). The group treated with $\mathrm{H}_{2} \mathrm{O}_{2}$ presented the lowest levels of pyruvate $\left(-2.65 \pm 0.57 \mathrm{nmol} / 10^{6}\right.$ cells $)$. The media supplemented with VC $(600 \mu \mathrm{M})$, and HYP $(100$ and $500 \mu \mathrm{M})$, in the presence of $\mathrm{H}_{2} \mathrm{O}_{2},(-2.00 \pm 0.83 ;-2.11 \pm 0.81$ and $-2.08 \pm$ $0.74 \mathrm{nmol} / 10^{6}$ cells, respectively) presented similar pyruvate levels to the $\mathrm{H}_{2} \mathrm{O}_{2}$-only group, which were significantly lower when compared to the control group and the antioxidantsonly groups (Fig. 6A).

Regarding acetate media levels, we found that media supplementation with VC $(600 \mu \mathrm{M})$ $\left(3.72 \pm 1.09 \mathrm{nmol} / 10^{6}\right.$ cells $)$ and HYP $(500 \mu \mathrm{M})\left(3.49 \pm 1.27 \mathrm{nmol} / 10^{6}\right.$ cells $)$, presented an increase in acetate production by spermatozoa compared to the control group $(2.65 \pm 0.76$ $\mathrm{nmol} / 10^{6}$ cells). However, no differences were found between the acetate levels of the HYP $(100 \mu \mathrm{M})$ group $\left(2.66 \pm 0.56 \mathrm{nmol} / 10^{6}\right.$ cells $)$ and the control group. On the other hand, we observed higher levels of acetate in the medium of spermatozoa treated only with $\mathrm{H}_{2} \mathrm{O}_{2}(7.11$ $\pm 1.25 \mathrm{nmol} / 10^{6}$ cells) (Fig. 6B). The levels of acetate in spermatozoa from VC $(600 \mu \mathrm{M})$ plus $\mathrm{H}_{2} \mathrm{O}_{2}$ group $\left(6.80 \pm 1.52 \mathrm{nmol} / 10^{6}\right.$ cells $)$ and the $\mathrm{HYP}(500 \mu \mathrm{M})$ plus $\mathrm{H}_{2} \mathrm{O}_{2}$ group $(7.04 \pm$ $1.59 \mathrm{nmol} / 10^{6}$ cells) were similar to the acetate levels of the $\mathrm{H}_{2} \mathrm{O}_{2}$-only group. Nevertheless, we also ascertain that acetate levels in the media of spermatozoa preserved in media supplemented with HYP $(100 \mu \mathrm{M})$ plus $\mathrm{H}_{2} \mathrm{O}_{2}\left(6.35 \pm 1.51 \mathrm{nmol} / 10^{6}\right.$ cells $)$ were lower than in the only- $\mathrm{H}_{2} \mathrm{O}_{2}$ group (Fig. 6B).

Concerning lactate media levels, no differences were found regarding the lactate levels of the control group ( $24.02 \pm 12.43 \mathrm{nmol} / 10^{6}$ cells), the ones supplemented with VC $(600 \mu \mathrm{M})$, and HYP $(100$ and $500 \mu \mathrm{M})(22.36 \pm 11.85 ; 26.11 \pm 14.05$ and $21.67 \pm 10.10$ $\mathrm{nmol} / 10^{6}$ cells, respectively). Lactate production by spermatozoa was decreased in the group treated with only $\mathrm{H}_{2} \mathrm{O}_{2}\left(10.79 \pm 7.23 \mathrm{nmol} / 10^{6}\right.$ cells $)$ in comparison with control and the antioxidant-only groups. In addition, the levels of lactate of the media supplemented with VC $(600 \mu \mathrm{M})$ and the HYP $(100$ and $500 \mu \mathrm{M})$, in the presence of $\mathrm{H}_{2} \mathrm{O}_{2}(15.28 \pm 7.07$; $13.12 \pm 7.17$ and $13.14 \pm 6.46 \mathrm{nmol} / 10^{6}$ cells, respectively) were similar to the lactate levels of the $\mathrm{H}_{2} \mathrm{O}_{2}$-only group (Fig. $6 \mathrm{C}$ ) and lower when compared to the control group and the antioxidants-only groups.

Interestingly, the media of spermatozoa preserved with HYP (100 and $500 \mu \mathrm{M})$ presented higher levels of alanine (0.93 \pm 0.60 and $1.00 \pm 0.77 \mathrm{nmol} / 10^{6}$ cells, respectively) when compared with the control group $\left(0.61 \pm 0.65 \mathrm{nmol} / 10^{6}\right.$ cells $)$, and the one supplemented with VC $(600 \mu \mathrm{M})\left(0.53 \pm 0.44 \mathrm{nmol} / 10^{6}\right.$ cells $)$. As seen in other metabolites, the media with only $\mathrm{H}_{2} \mathrm{O}_{2}$ supplementation $\left(0.12 \pm 0.48 \mathrm{nmol} / 10^{6}\right.$ cells $)$, and the media supplemented with VC $(600 \mu \mathrm{M})$ and HYP $(100$ and $500 \mu \mathrm{M})$, in the presence of $\mathrm{H}_{2} \mathrm{O}_{2}(0.13 \pm 0.31 ; 0.20 \pm 0.31$ and $0.25 \pm 0.34 \mathrm{nmol} / 10^{6}$ cells, respectively) presented decreased alanine levels when compared to the control and antioxidants-only groups (Fig. 6D).

Concerning malate variation, no differences were found in media malate levels between the control group $\left(14.36 \pm 17.04 \mathrm{nmol} / 10^{6}\right.$ cells $)$ and the ones supplemented with VC $(600 \mu \mathrm{M})$, and HYP $(100$ and $500 \mu \mathrm{M})(11.63 \pm 11.39 ; 12.95 \pm 11.56$ and $20.00 \pm 15.63$ $\mathrm{nmol} / 10^{6}$ cells). The $\mathrm{H}_{2} \mathrm{O}_{2}$-only group presented the lowest malate levels $(1.25 \pm 2.76$ $\mathrm{nmol} / 10^{6}$ cells) in comparison to the control and the antioxidant-only groups. Decreased malate levels were also in media supplemented with VC $(600 \mu \mathrm{M})$ and HYP $(100$ and $500 \mu \mathrm{M})$, in the presence of $\mathrm{H}_{2} \mathrm{O}_{2},\left(2.71 \pm 4.66 ; 7.21 \pm 6.02\right.$ and $4.33 \pm 5.46 \mathrm{nmol} / 10^{6}$ cells, respectively) (Fig. 6E). 


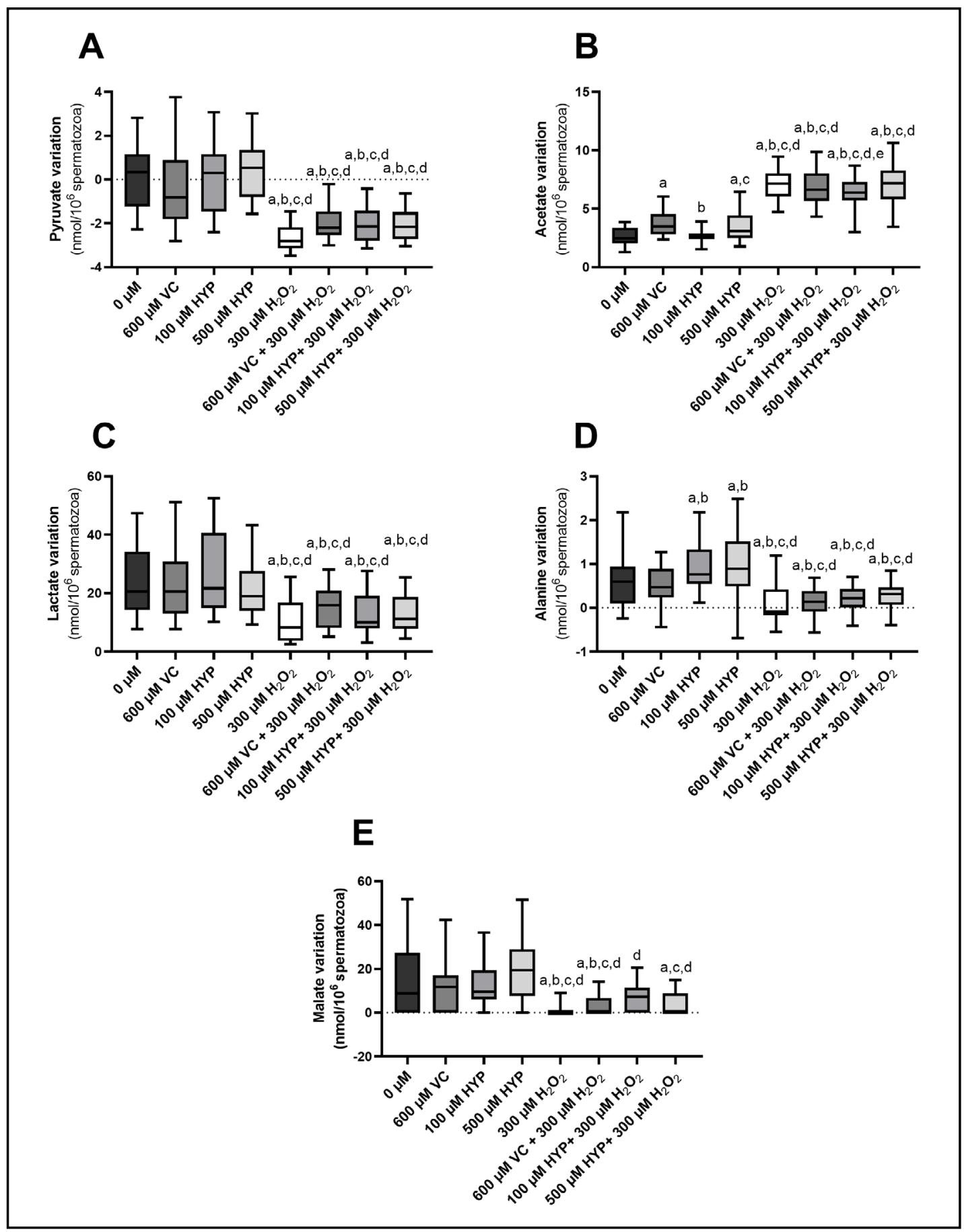

Fig. 6. Effects of vitamin C (VC) and hyperoside (HYP) media supplementation under oxidative stress conditions, in pyruvate (A), acetate (B), lactate (C), alanine (D), and malate (E) levels found in the sperm preservation media. All results are represented as Tukey's whisker boxes (median, $25^{\text {th }}$ to 75 th percentiles \pm minimum and maximum values). Significantly different results (one-way ANOVA followed by the correction for multiple comparisons by controlling FDR, two-stage step-up method of Benjamini, Krieger, and Yekutieli; $\mathrm{p}<0.05$ ) are indicated as (a) relative to control $(0 \mu \mathrm{M})$; (b) relative to $600 \mu \mathrm{M}$ VC group; (c) relative to $100 \mu \mathrm{M}$ HYP group; (d) relative to $500 \mu \mathrm{M}$ HYP group; (e) relative to $300 \mu \mathrm{M} \mathrm{H}_{2} \mathrm{O}_{2}$ group. 


\section{Cellular Physiology Cell Physiol Biochem 2022;56(S1):1-23

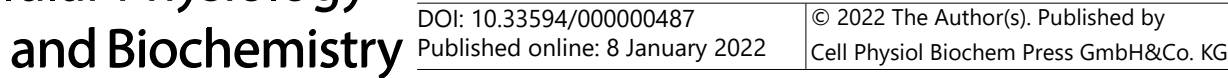 \\ Moreira et al:: Vitamin C and Hyperoside Protect Human Spermatozoa}

\section{Discussion}

ROS are part of the complex signalling network used by cells. In spermatozoa, ROS participate in several physiological events such as capacitation, hyperactivation, acrosomal reaction, and sperm-oocyte fusion [7-9]. These events are essential for sperm function and to ensure a successful pregnancy. Nevertheless, the overproduction of ROS is responsible for the increase of deleterious events such as lipid peroxidation [10] (that severely impacts sperm membranes), protein modifications [11], DNA fragmentation [12], and others. Consequently, it is possible to correlate the rise of ROS in the male reproductive tract with a loss of sperm motility [13], morphology [14], and loss of male fertility capacity in general [15]. These infertile individuals often recur to ART to pursue parenthood. However, the gametes' preparation for these techniques often increases the exposure of gametes and embryos to ROS. For spermatozoa, the removal of seminal plasma, as well as sperm processing techniques (centrifugation, light exposure, temperature variations) cause an increase in ROS production and with that a decrease in the chances of achieving a successful pregnancy [18]. To protect gametes and embryos from excessive ROS, culture media are often supplemented with antioxidants.

In this work, we studied the effects of VC $(600 \mu \mathrm{M})$ and HYP $(100$ and $500 \mu \mathrm{M})$ supplementation on sperm media, under an exacerbated OS condition. According to the WHO manual for semen analysis [43], after semen collection, samples should be treated as soon as possible, not surpassing the 1-hour time-point, to better preserve spermatozoa physiology [43]. Taking this into consideration, we established the timeframe of $1 \mathrm{~h}$ to test the cytoprotective effects of VC and HYP media supplementation on spermatozoa. The dosage of VC was chosen based on several studies [40, 42, 51]. The existing literature describes the seminal plasma VC levels to vary between 200-700 $\mu \mathrm{M}$. We established the concentration of $600 \mu \mathrm{M}$ of $\mathrm{VC}$ to act as the antioxidant control for our study [40,42, 51]. Considering the lack of literature about the potential effects of HYP on human spermatozoa, a cytotoxicity test was performed with a range of HYP concentrations $(0,5,50,100$, and $500 \mu \mathrm{M})$. These concentrations were chosen considering the existent data regarding the flavonol quercetin, the hyperoside aglycone $[49,52]$. Similar to these works, we studied the cytotoxicity effects of HYP to spermatozoa by evaluation of sperm motility and vitality after the treatment. Since we could not detect any alterations regarding sperm motility and vitality after the $1 \mathrm{~h}$ treatment with increasing doses of HYP, the concentration of 100 and $500 \mu \mathrm{M}$ were chosen for further testing. This decision was based on the published works regarding the antioxidant effects of quercetin in human spermatozoa $[49,52]$.

In our study design, we used $\mathrm{H}_{2} \mathrm{O}_{2}$ as an OS-inducer. However, existing literature regarding the $\mathrm{OS}$-inducer potential of $\mathrm{H}_{2} \mathrm{O}_{2}$ in in vitro studies of spermatozoa is very divergent. Evdokimov, V., and colleagues [53] showed that after $1 \mathrm{~h}$ of incubation in the presence of $100 \mu \mathrm{M}$ of $\mathrm{H}_{2} \mathrm{O}_{2}$, there was an increase in the progressive motility of spermatozoa, while other authors report a decrease of $36 \%$ in progressive motility after $1 \mathrm{~h}$ with $120 \mu \mathrm{M} \mathrm{of} \mathrm{H}_{2} \mathrm{O}_{2}$ [45]. Otherwise, it was proven that higher concentrations of $\mathrm{H}_{2} \mathrm{O}_{2}(600 \mu \mathrm{M})$ cause a drastic reduction in sperm motility and viability after 10 minutes of incubation [44, 45]. In order to promote OS in spermatozoa, but not induce a total immobilization (and death), we selected the concentration of $300 \mu \mathrm{M}$ of $\mathrm{H}_{2} \mathrm{O}_{2}$ for our study. According to our results, this concentration of $\mathrm{H}_{2} \mathrm{O}_{2}$ was able to induce a severe decrease in sperm motility, while no alterations regarding sperm vitality were detected. Thereby the effects observed in sperm motility are not due to cell death but a consequence of the effect of $\mathrm{H}_{2} \mathrm{O}_{2}$ on motility machinery. As in other studies, sperm motility was chosen as the main indicator of sperm function $[49,52]$. Furthermore, sperm motility can be severely affected by OS, probably through inhibition of glucose-6phosphate dehydrogenase (G6PD) by $\mathrm{H}_{2} \mathrm{O}_{2}$, leading to a decrease in the availability of NADPH and the consequent peroxidation of membrane lipids $[10,54]$. In turn, lipid peroxidation leads to the formation of reactive aldehyde compounds, such as 4-HNE, that are linked to numerous adverse effects on sperm function [55-57]. 
Our results revealed that the incubation of spermatozoa in media supplemented with VC $(600 \mu \mathrm{M})$ and HYP $(100$ and $500 \mu \mathrm{M})$ for $1 \mathrm{~h}$ did not induce deleterious effects in human spermatozoa. The spermatozoa motility after incubation in the antioxidant-only supplemented groups was similar to that of the control group. Also, there were no alterations in the expression of OS biomarkers in these groups. The levels of DNA fragmentation, as well as the MMP, were also similar between the control group and the antioxidant-only supplemented groups. To our knowledge, there is no information regarding the impact of HYP in the physiological and metabolic biomarkers assessed in this work. However, some authors have already studied the impact of VC medium supplementation in spermatozoa [58, 59]. Raad G. and colleagues supplemented sperm swim-up medium with increasing doses of VC (in $\mu \mathrm{M}: 0,300$, and 600). The swim-up technique is used for sperm differentiation and isolation, and it is based on the movement of pre-washed spermatozoa. Only spermatozoa with normal physiology can swim up into the overlying medium. Similar to our results, the authors could not find any alteration in sperm-quality parameters (morphology and motility), after the swim-up procedure with and without VC (300 and $600 \mu \mathrm{M})$ [58]. Nevertheless, the concentration of $300 \mu \mathrm{M} \mathrm{VC}$ presented lower levels of abnormal chromatin integrity in comparison to the raw semen sample [58]. Our results did not reveal any alteration in the percentage of DNA fragmentation between the control group and the antioxidantsupplemented groups after $1 \mathrm{~h}$ treatment. However, we must take into consideration that Raad G. and colleagues only considered the spermatozoa from the overlying medium, after the swim-up technique. Abnormal spermatozoa are an endogenous source of ROS, and the fact that we used the total sperm sample could be the reason no statistical differences were found between our control group and the antioxidant-supplemented groups [58]. The authors also reported that the concentration of $600 \mu \mathrm{M}$ of VC did not affect ROS generation. This finding is in line with results reported by another group, Li and colleagues, which reported that the supplementation of cryopreservation medium with VC $(300 \mu \mathrm{M})$ significantly reduced the ROS levels in post-thaw spermatozoa [59]. Nevertheless, the concentration of $600 \mu \mathrm{M} \mathrm{VC}$ did not show any difference regarding ROS generation [59]. Li and colleagues justified this result by the fact that $\mathrm{VC}$ presents a scavenger activity mainly against. $\mathrm{OH}$ and $\mathrm{O}_{2}$; which are important substrates for $\mathrm{H}_{2} \mathrm{O}_{2}$ formation. The product of this reaction is ascorbyl radical $\mathrm{A}$ which induces a series of radical free reactions if accumulated in higher doses [59]. Our results are in accordance with both these studies since we could not find any difference between the expression of OS biomarkers in spermatozoa in the groups treated with antioxidants-only and the control group.

As a haploid cell with a high motility activity, spermatozoa metabolism has been explored in the last decades. Energy production in spermatozoa can occur through two metabolic pathways, namely oxidative phosphorylation (OXPHOS), which occurs in the mitochondria, and glycolysis, which occurs in the head and the flagellum [60]. Regarding those pathways, there are conflicting data about the main source of ATP in human spermatozoa. It is proposed that the ATP produced by OXPHOS contributes to human sperm motility, but it is not enough to sustain high motility [61]. Meanwhile, other researchers showed that an increased mitochondrial respiratory capacity is associated with increased sperm motility, supporting the crucial role played by OXPHOS in human sperm [62, 63]. During glycolysis, glucose enters the cell and is decomposed by a sequence of events originating ATP and pyruvate as by-products. Apart from glycolysis, pyruvate can also be generated by the oxidation of lactate or by the transamination of alanine via alanine aminotransferase (ALT). Then, pyruvate can either be oxidized to acetyl coenzyme A, which can enter the tricarboxylic acid (TCA) cycle, to generate ATP via OXPHOS, or be converted to lactate via lactate dehydrogenase (LDH) in the cytosol. The latter reaction results in the regeneration of cytosolic $\mathrm{NAD}^{+}$, which is essential for glycolysis [64]. $\mathrm{NAD}^{+}$and $\mathrm{NADH}$ cannot cross the inner mitochondrial membrane and for this reason are dependent on a system that transfers reducing equivalents to mitochondria, the malate-aspartate shuttle (MAS). In the cytosol, malate dehydrogenase (MDH) reduces oxaloacetate (OAA) to malate, through oxidation of $\mathrm{NADH}$ to $\mathrm{NAD}^{+}$, which then enters in mitochondria. Once in mitochondria, the reverse reaction is performed by $\mathrm{MDH}$, mediating 
the regeneration of NADH $[65,66]$. Herein, malate is a metabolite that plays a crucial role in mitochondrial respiration, being part of the TCA cycle and participating in the restoration of mitochondrial NADH levels $[67,68]$. We could not find any data regarding the impact of VC and HYP media supplementation on the metabolism of spermatozoa. Therefore, we analysed human spermatozoa metabolism through quantification of metabolites in the sperm preservation media by ${ }^{1} \mathrm{H}-\mathrm{NMR}$. We were able to quantify pyruvate, acetate, lactate, alanine, and malate. Although we could not find any differences between the control and antioxidants-only media regarding pyruvate, lactate, and malate levels, some interesting differences were found regarding the levels of alanine and acetate. The levels of alanine were higher in the media supplemented with HYP $(100$ and $500 \mu \mathrm{M})$, in comparison to the control and those supplemented with VC. No differences between the control group and the media supplemented with VC $(600 \mu \mathrm{M})$ were found regarding alanine levels. As mentioned, alanine is mostly used as a source of pyruvate, through the process of alanine transamination [64]. Since the pyruvate levels remain the same between the control and the antioxidant-only groups, HYP may induce the formation of alanine to act as a metabolite reservoir. The levels of acetate were higher when VC $(600 \mu \mathrm{M})$ and HYP $(500 \mu \mathrm{M})$ were present in the media than in the control, though no difference was found between the control group and the $100 \mu \mathrm{M}$ HYP supplemented group. Acetate and the related metabolism of acetyl-coenzyme A are known to play several roles in the cell, including lipid biosynthesis and energy production [69]. A previous study conducted by our group showed that Sertoli cells (SCs) produce and excrete large amounts of acetate into the extracellular medium [70]. In addition, a recent study performed in human spermatozoa found considerable amounts of acetate in the sperm medium [71]. Herein, we hypothesized that the higher levels of acetate in media supplemented with VC $(600 \mu \mathrm{M})$ and HYP $(500 \mu \mathrm{M})$, which are the groups with higher amounts of antioxidant, can be associated with a higher rate of lipid biosynthesis.

The scenario changed when we added $\mathrm{H}_{2} \mathrm{O}_{2}$ as an OS-inducer. As mentioned, the incubation of spermatozoa with $\mathrm{H}_{2} \mathrm{O}_{2}$ severely decreased sperm motility in comparison to the control group and the spermatozoa incubated in media with antioxidants, even though no alterations were found regarding sperm vitality. This group subjected to $\mathrm{H}_{2} \mathrm{O}_{2}$ also presented the highest levels of sperm lipid peroxidation and the highest levels of DNA fragmentation. Our results also demonstrate that the presence of VC and HYP in the media was able to revert some of the oxidative damage induced by $\mathrm{H}_{2} \mathrm{O}_{2}$. Although the spermatozoa incubated with the antioxidants in the presence of $\mathrm{H}_{2} \mathrm{O}_{2}$ did also present a decrease in sperm motility, this decline was not as accentuated as in the one subjected to $\mathrm{H}_{2} \mathrm{O}_{2}$-only. This pattern can also be observed regarding sperm lipid peroxidation and DNA fragmentation levels. However, the decrease of MMP in spermatozoa incubated with antioxidant plus $\mathrm{H}_{2} \mathrm{O}_{2}$ was not different from the decrease of MMP observed in the spermatozoa incubated only with $\mathrm{H}_{2} \mathrm{O}_{2}$. The antioxidant cytoprotective effects of HYP have already been reported for both lung fibroblast cells, and granulosa cells [26, 27]. In sperm cells, Biagi M and colleagues used a $C$. sativa leaf extract (rich in HYP) to study its protective properties against OS [28], though the particular effects of HYP were not directly explored. The authors incubated swim-up selected spermatozoa with several dilutions of $C$. sativa leaf extract in Biggers-Whitten-Whittingham (BWW) buffer $\left(1: 100,1: 200\right.$, and 1:500). $\mathrm{H}_{2} \mathrm{O}_{2}(100 \mu \mathrm{M})$ was used as an OS-inducer. Similar to our results, the incubation of spermatozoa with the $C$. sativa leaf extract did not decrease sperm motility in comparison to the control group. Furthermore, the authors reported a rise in lipid peroxidation levels of spermatozoa incubated with $\mathrm{H}_{2} \mathrm{O}_{2}$. Nevertheless, when spermatozoa were incubated with the $C$. sativa leaf extract in the presence of $\mathrm{H}_{2} \mathrm{O}_{2}$, the lipid peroxidation levels remain similar to the control [28]. Our results are in line with this study since we reported that the presence of HYP $(100$ and $500 \mu \mathrm{M})$ showed a tendency to decrease lipid peroxidation levels associated with high OS induced by the presence of $\mathrm{H}_{2} \mathrm{O}_{2}$. Zribi N. and colleagues supplemented sperm cryopreservation medium with quercetin $(50 \mu \mathrm{M})$ [72]. Although the process of cryopreservation induced an increase in sperm DNA fragmentation, the quercetin supplementation was able to improve post-thaw sperm parameters and DNA integrity [72]. These quercetin proprieties were also described in several animal sperm 
studies [73-75]. Our results regarding sperm media supplementation with HYP are in line with these quercetin studies. Our results show that the supplementation of sperm medium with HYP $(100 \mu \mathrm{M})$ was able to prevent some of the deleterious effects of $\mathrm{H}_{2} \mathrm{O}_{2}$ in sperm, which is represented by an increase in sperm motility, a decrease in DNA fragmentation, and a decreasing trend in lipid peroxidation levels when compared to the spermatozoa under $\mathrm{H}_{2} \mathrm{O}_{2}$ effect.

Mangoli E. and colleagues reported that the addition of VC $(600 \mu \mathrm{M})$ in both neat semen and prepared spermatozoa of normozoospermic samples improved the recovery rate of sperm parameters and DNA integrity following vitrification [40]. A similar result was found by Fanaei H. and colleagues, which incubated swim-up spermatozoa with VC (600 $\mu \mathrm{M})$ [42]. The authors reported decreased DNA fragmentation levels, reduced lipid peroxidation levels, and an improvement in sperm quality parameters (motility and viability) in comparison to spermatozoa in the control group [42]. This scavenger and DNA protective effect of VC addition has already been described by several authors $[42,58,76]$. Our findings are in accordance with these studies since the sperm media supplemented with antioxidants (VC and HYP) were able to preserve sperm motility and decrease DNA fragmentation when compared to the spermatozoa under the effect of $\mathrm{H}_{2} \mathrm{O}_{2}$. Additionally, the supplementation with these antioxidants also evidenced a tendency to decrease lipid peroxidation levels in oxidative stress conditions.

Nevertheless, our results suggest that VC and HYP cannot reverse the deleterious effects of $\mathrm{H}_{2} \mathrm{O}_{2}$ regarding sperm metabolism. Interestingly, incubation of spermatozoa with $\mathrm{H}_{2} \mathrm{O}_{2}$ promoted a decrease of pyruvate levels in the medium, in comparison to those in the control and supplemented with antioxidants. Pyruvate is a pivotal metabolite that takes part in several metabolic pathways. To understand the metabolic pathways that were promoted by $\mathrm{H}_{2} \mathrm{O}_{2}$, we investigated how the levels of several other metabolites varied. It was previously reported that pyruvate is mainly converted to lactate in human sperm $[77,78]$. The decrease in lactate production found in all groups with $\mathrm{H}_{2} \mathrm{O}_{2}$, even in the presence of VC and HYP, indicates that it is unlikely for spermatozoa to be producing energy by anaerobic respiration. Alanine production also decreased in the presence of $\mathrm{H}_{2} \mathrm{O}_{2}$, even when media is supplemented with VC and HYP. Since pyruvate consumption levels are higher in media with $\mathrm{H}_{2} \mathrm{O}_{2}$, spermatozoa might be using alanine as a source of pyruvate through the process of alanine transamination [64]. To further understand mitochondria function from the spermatozoa of these groups, we can correlate the malate levels and the MMP results. As mentioned, all groups incubated with $\mathrm{H}_{2} \mathrm{O}_{2}$, even in the presence of antioxidants, presented a decrease in the MMP. Along with that, all these groups also presented a decrease in the production of malate. Malate is an important component of mitochondrial metabolism [65, 66]. The lower MMP and malate levels found in the groups of spermatozoa treated in the presence of $\mathrm{H}_{2} \mathrm{O}_{2}$ suggest a decline in mitochondrial activity, which can also be related to loss of motility in those groups. Therefore, the higher consumption of pyruvate found in these groups appears to not be redirected to the mitochondrial metabolism. Nevertheless, we found that the production of acetate was increased in all $\mathrm{H}_{2} \mathrm{O}_{2}$-treated groups. The overproduction of acetate is known to be promoted by situations of exacerbated OS [69]. In fact, the reaction of exogenous pyruvate with $\mathrm{H}_{2} \mathrm{O}_{2}$ is known to induce the formation of acetate, carbon dioxide, and water [79]. In addition, it is also reported that under severe OS situations, pyruvate can exert a protective effect on several cellular systems, acting as a peroxide scavenger [79]. In normal conditions, pyruvate plays a little role in the clearance of $\mathrm{H}_{2} \mathrm{O}_{2}$ since its concentration and availability are regulated by metabolism. Several authors have explored the antioxidant role of pyruvate in the brain of mice since neurons are highly susceptible to OS $[79,80]$. In human cells, Babich $\mathrm{H}$. and colleagues studied the susceptibility of human fibroblast cells to $\mathrm{H}_{2} \mathrm{O}_{2}$ when treated in culture media with and without pyruvate, where a cytoprotective action of pyruvate was observed [81]. Having this in consideration, we propose that the decrease of pyruvate levels found in the media of spermatozoa treated with $\mathrm{H}_{2} \mathrm{O}_{2}$ is likely caused by its reaction with $\mathrm{H}_{2} \mathrm{O}_{2}$, forming acetate, carbon dioxide, and water in the process. Given the important role that pyruvate plays in cellular energy production, we 


\section{Cellular Physiology Cell Physiol Biochem 2022;56(S1):1-23 \\ \begin{tabular}{ll|l} 
and Biochemistry $10.33594 / 000000487$ & $\begin{array}{l}\text { D } 2022 \text { The Author(s). Published by } \\
\text { Published online: } 8 \text { January } 2022\end{array}$ \\
\cline { 2 - 3 } & Cell Physiol Biochem Press GmbH\&Co. KG
\end{tabular} \\ Moreira et al.: Vitamin $\mathrm{C}$ and Hyperoside Protect Human Spermatozoa}

hypothesize that the overflow of pyruvate to acetate can disrupt spermatozoa metabolism. Due to the unavailability of pyruvate, other metabolic pathways, such as anaerobic and aerobic respiration are compromised. This would also justify the loss of sperm motility found in the groups treated with $\mathrm{H}_{2} \mathrm{O}_{2}$, even in the presence of antioxidants. Nevertheless, the loss of motility was attenuated by the antioxidants' presence. Notwithstanding, the levels of acetate found in the group treated with HYP $(100 \mu \mathrm{M})$ plus $\mathrm{H}_{2} \mathrm{O}_{2}$ were lower than the levels of acetate found in the spermatozoa treated with $300 \mu \mathrm{M} \mathrm{H}_{2} \mathrm{O}_{2}$. This could indicate that supplementation with $100 \mu \mathrm{M}$ of HYP is more efficient in the protection of spermatozoa towards $\mathrm{H}_{2} \mathrm{O}_{2}$, most likely through a better neutralization of the available $\mathrm{H}_{2} \mathrm{O}_{2}$.

Our findings demonstrate that HYP and VC were effective in protecting human spermatozoa against oxidative damage. Nevertheless, the treatment with HYP $(100 \mu \mathrm{M})$ presented better results regarding sperm preservation than HYP $(500 \mu \mathrm{M})$ and VC $(600 \mu \mathrm{M})$. Also, HYP was shown to be more effective than VC $(600 \mu \mathrm{M})$ since lower concentrations of HYP presented similar protective effects in human spermatozoa. Previous studies reported that VC stability is influenced by $\mathrm{pH}$, temperature, oxygen, and the presence of metal ions, such as copper and iron [82, 83]. VC decomposes rather quickly in an aqueous medium, and its oxidation is highly favoured in neutral or basic conditions, being the lowest rate of oxidation observed at pH 3 [84]. On the other hand, a recent study showed that HYP is stable at $\mathrm{pH} 4-8$, remains unchanged at temperatures between $25-40{ }^{\circ} \mathrm{C}$ and presents an excellent photostability [85]. The stability of HYP under physiological conditions (pH 7.4) combined with its high antioxidant capacity enhances the use of this phytochemical in sperm preservation solutions.

\section{Conclusion}

For all the aforementioned, we concluded that the supplementation of sperm preservation media with VC and with HYP can be beneficial for the preservation of spermatozoa to ART protocols. These antioxidants appear to present cytoprotective proprieties to human spermatozoa, preserving sperm motility and preventing DNA fragmentation, under oxidative stress conditions. Also, these antioxidants appear to prevent (to some extent) the lipid peroxidation of the spermatozoa membranes from oxidative injury. Our findings evidence that HYP holds a higher antioxidant capacity than VC since the concentration of $100 \mu \mathrm{M}$ of HYP presented the best results regarding spermatozoa physiology and metabolism. Notwithstanding, the deleterious effects promoted by $\mathrm{H}_{2} \mathrm{O}_{2}$ found in mitochondrial activity and sperm metabolism could not be reversed by the presence of VC and HYP in the sperm media. To our knowledge, this is the first study to explore the role of HYP as an antioxidant supplement of sperm medium and the first to explore the metabolic consequences of the presence of VC and HYP in sperm preservation medium. Nevertheless, the ideal doses of these antioxidants for the most effective cytoprotective effects in human sperm cells need to be further explored.

\section{Acknowledgements}

\section{Author Contributions}

MVM participated in the conception, and design of the article, from the acquisition of data to bibliographic search, analysis, writing, illustration, data interpretation, and critical discussion. SCP participated in the conception, and design of this article, acquisition of data, bibliographic search, analysis, writing, data interpretation, and critical discussion. BGC participated in the acquisition of ${ }^{1} \mathrm{H}-\mathrm{NMR}$ spectra, spectra analysis, data interpretation, and critical discussion. DFC participated in the acquisition of ${ }^{1} \mathrm{H}-\mathrm{NMR}$ spectra and spectra analysis. SP provided the clinical support for this work, collecting samples and clinical data, and participating in the data analysis/ interpretation. $\mathrm{AB}$ provided a medical perspective 


\section{Cellular Physiology Cell Physiol Biochem 2022;56(S1):1-23 \\ \begin{tabular}{c|c|c|c|} 
Dol: 10.33594/000000487 2022 & O 2022 The Author(s). Published by \\
Ceell Physiol Biochem Press GmbHerco
\end{tabular} \\ Moreira et al.: Vitamin $\mathrm{C}$ and Hyperoside Protect Human Spermatozoa}

to the discussion of the article. BMS, MGA, and PFO contributed to article conception and design, writing, bibliographic enrichment, data interpretation, and critical discussion. All authors approved the final version for submission.

\section{Funding}

This work was supported by Fundação para a Ciência e a Tecnologia - FCT to Sara C. Pereira (2021.05487.BD); David F. Carrageta (SFRH/BD/136779/2018); Marco G. Alves (IFCT2015 and PTDC/MEC-AND/28691/2017); LAQV-REQUIMTE (UIDB/50006/2020); UMIB (UIDB/00215/2020, and UIDP/00215/2020); ITR - Laboratory for Integrative and Translational Research in Population Health (LA/P/0064/2020). Pedro F. Oliveira was funded by national funds through FCT - Fundação para a Ciência e a Tecnologia, I.P., under the Scientific Employment Stimulus - Institutional Call - reference CEECINST/00026/2018.

\section{Statement of Ethics}

This study was approved by the Joint Ethics Committee of Centro Hospitalar Universitário do Porto (CHUP)/Institute of Biomedical Sciences Abel Salazar CHUP/ICBAS (2021/CE/ P002[P342/CETI/ICBAS]). All procedures were performed in accordance with the local, national, and European ethical guidelines. All patients participated in this study voluntarily. They were informed about the purpose of the study and signed informed written consent.

\section{Disclosure Statement}

The authors have no conflicts of interest to declare.

\section{References}

1 Agarwal A, Mulgund A, Hamada A, Chyatte MR: A unique view on male infertility around the globe. Reprod Biol Endocrinol 2015;13:1-9.

2 Alahmar AT: Role of Oxidative Stress in Male Infertility: An Updated Review. J Hum Reprod Sci 2019;12:418.

3 Agarwal A, Parekh N, Panner Selvam MK, Henkel R, Shah R, Homa ST, Ramasamy R, Ko E, Tremellen K, Esteves S, Majzoub A, Alvarez JG, Gardner DK, Jayasena CN, Ramsay JW, Cho CL, Saleh R, Sakkas D, Hotaling JM, Lundy SD, et al.: Male Oxidative Stress Infertility (MOSI): Proposed Terminology and Clinical Practice Guidelines for Management of Idiopathic Male Infertility. World J Mens Health 2019;37:296-312.

4 Sies H: Oxidative stress: a concept in redox biology and medicine. Redox Biol 2015;4:180-183.

5 Bisht S, Faiq M, Tolahunase M, Dada R: Oxidative stress and male infertility. Nat Rev Urol 2017;14:470-485.

6 Barati E, Nikzad H, Karimian M: Oxidative stress and male infertility: current knowledge of pathophysiology and role of antioxidant therapy in disease management. Cell Mol Life Sci 2020;77:93-113.

7 Griveau JF, Lannou DL: Reactive oxygen species and human spermatozoa: physiology and pathology. Int J Androl 1997;20:61-69.

8 de Lamirande E, Cagnon C: Human sperm hyperactivation and capacitation as parts of an oxidative process. Free Radic Biol Med 1993;14:157-166.

9 Aitken RJ, Irvine DS, Wu FC: Prospective analysis of sperm-oocyte fusion and reactive oxygen species generation as criteria for the diagnosis of infertility. Am J Obstet Gynecol 1991;164:542-551.

10 Griveau JF, Dumont E, Renard P, Callegari JP, Le Lannou D: Reactive oxygen species, lipid peroxidation and enzymatic defence systems in human spermatozoa. J Reprod Fertil 1995;103:17-26.

11 O’Flaherty C, Matsushita-Fournier D: Reactive oxygen species and protein modifications in spermatozoa. Biol Reprod 2017;97:577-585.

12 Villani P, Eleuteri P, Grollino MG, Rescia M, Altavista P, Spanò M, Pacchierotti F, Cordelli E: Sperm DNA fragmentation induced by DNAse I and hydrogen peroxide: an in vitro comparative study among different mammalian species. Reproduction (Cambridge, England) 2010;140:445-452. 


\section{Cellular Physiology Cell Physiol Biochem 2022;56(S1):1-23 \begin{tabular}{ll|l} 
and Biochemistry $10.33594 / 000000487$ & Published online: 8 January 2022 & $\begin{array}{l}\text { C } 2022 \text { The Author(s). Published by } \\
\text { Cell Physiol Biochem Press GmbH\&Co. KG }\end{array}$
\end{tabular} \\ Moreira et al.: Vitamin $\mathrm{C}$ and Hyperoside Protect Human Spermatozoa}

13 Kuroda S, Yumura Y, Mori K, Yasuda K, Takeshima T, Kawahara T, Miyoshi Y, Uemura H, Iwasaki A, Takashima K, Ikeda M, Kondo Y: Negative correlation between the presence of reactive oxygen species and Sperm Motility Index in whole semen samples of infertile males. Rev Int Androl 2017;15:84-89.

14 Aziz N, Saleh RA, Sharma RK, Lewis-Jones I, Esfandiari N, Thomas AJ, Jr., Agarwal A: Novel association between sperm reactive oxygen species production, sperm morphological defects, and the sperm deformity index. Fertil Steril 2004;81:349-354.

15 Yumura Y, Iwasaki A, Saito K, Ogawa T, Hirokawa M: Effect of reactive oxygen species in semen on the pregnancy of infertile couples. Int J Urol 2009;16:202-207.

16 Vernon M, Stern JE, Ball GD, Wininger D, Mayer J, Racowsky C: Utility of the national embryo morphology data collection by the Society for Assisted Reproductive Technologies (SART): correlation between day-3 morphology grade and live-birth outcome. Fertil Steril 2011;95:2761-2763.

17 Agarwal A, Said TM, Bedaiwy MA, Banerjee J, Alvarez JG: Oxidative stress in an assisted reproductive techniques setting. Fertil Steril 2006;86:503-512.

18 Gupta S, Sekhon L, Kim Y, Agarwal A: The role of oxidative stress and antioxidants in assisted reproduction. Curr Women's Health Rev 2010;6:227-238.

19 Zou Y, Lu Y, Wei D: Antioxidant activity of a flavonoid-rich extract of Hypericum perforatum L. in vitro. J Agric Food Chem 2004;52:5032-5039.

20 Orhan I, Özçelik B, Kartal M, Özdeveci B, Duman H: HPLC quantification of vitexine-2 "-O-rhamnoside and hyperoside in three Crataegus species and their antimicrobial and antiviral activities. Chromatographia 2007;66:153-157.

21 Pei J, Chen A, Zhao L, Cao F, Ding G, Xiao W: One-Pot Synthesis of Hyperoside by a Three-Enzyme Cascade Using a UDP-Galactose Regeneration System. J Agric Food Chem 2017;65:6042-6048.

22 Liu YH, Liu GH, Mei JJ, Wang J: The preventive effects of hyperoside on lung cancer in vitro by inducing apoptosis and inhibiting proliferation through Caspase-3 and P53 signaling pathway. Biomed Pharmacother 2016;83:381-391.

23 Ku SK, Zhou W, Lee W, Han MS, Na M, Bae JS: Anti-inflammatory effects of hyperoside in human endothelial cells and in mice. Inflammation 2015;38:784-799.

24 Ku SK, Kim TH, Lee S, Kim SM, Bae JS: Antithrombotic and profibrinolytic activities of isorhamnetin-3-0galactoside and hyperoside. Food Chem Toxicol 2013;53:197-204.

25 Zheng M, Liu C, Pan F, Shi D, Zhang Y: Antidepressant-like effect of hyperoside isolated from Apocynum venetum leaves: possible cellular mechanisms. Phytomedicine 2012;19:145-149.

26 Piao MJ, Kang KA, Zhang R, Ko DO, Wang ZH, You HJ, Kim HS, Kim JS, Kang SS, Hyun JW: Hyperoside prevents oxidative damage induced by hydrogen peroxide in lung fibroblast cells via an antioxidant effect. Biochimica et biophysica acta General subjects 2008;1780:1448-1457.

27 Wang X, Fan G, Wei F, Bu Y, Huang W: Hyperoside protects rat ovarian granulosa cells against hydrogen peroxide-induced injury by sonic hedgehog signaling pathway. Chem Biol Interact 2019;310:108759.

28 Biagi M, Noto D, Corsini M, Baini G, Cerretani D, Cappellucci G, Moretti E: Antioxidant effect of the Castanea sativa Mill. leaf extract on oxidative stress induced upon human spermatozoa. Oxid Med Cell Longev 2019;2019:8926075.

29 Pehlivan F: Vitamin C: An Antioxidant Agent; in Hamza AH (eds): Vitamin C. IntechOpen, 2017, pp 25-33.

30 Lykkesfeldt J, Michels AJ, Frei B: Vitamin C. Adv Nutr 2014;5:16-18.

31 Colagar AH, Marzony ET: Ascorbic Acid in human seminal plasma: determination and its relationship to sperm quality. J Clin Biochem Nutr 2009;45:144-149.

32 Fraga CG, Motchnik PA, Shigenaga MK, Helbock HJ, Jacob RA, Ames BN: Ascorbic acid protects against endogenous oxidative DNA damage in human sperm. Proc Natl Acad Sci U S A 1991;88:11003-11006.

33 Jacob RA, Planalto FS, Agee RE: Cellular ascorbate depletion in healthy men. J Nutr 1992;122:1111-1118.

34 Kandár R, Drábková P, Hampl R: The determination of ascorbic acid and uric acid in human seminal plasma using an HPLC with UV detection. J Chromatogr B Analyt Technol Biomed Life Sci 2011;879:2834-2839.

35 Thiele J, Freisleben HJ, Fuchs J, Ochsendorf F: Ascorbic acid and urate in human seminal plasma: Determination and interrelationships with chemiluminescence in washed semen. Hum Reprod 1995;10:110-115.

36 Abad C, Amengual MJ, Gosálvez J, Coward K, Hannaoui N, Benet J, García-Peiró A, Prats J: Effects of oral antioxidant treatment upon the dynamics of human sperm DNA fragmentation and subpopulations of sperm with highly degraded DNA. Andrologia 2013;45:211-216. 


\section{Cellular Physiology Cell Physiol Biochem 2022;56(S1):1-23

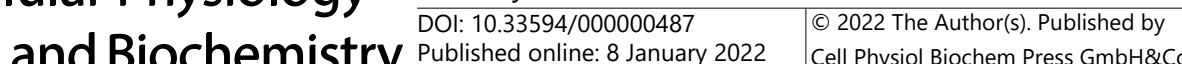 and Biochemistry Published online: 8 January 2022 Cell Physiol Biochem Press GmbH\&Co. KG \\ Moreira et al.: Vitamin C and Hyperoside Protect Human Spermatozoa}

37 Akmal M, Qadri JQ, Al-Waili N, Thangal S, Haq A, Saloom K: Improvement in Human Semen Quality After Oral Supplementation of Vitamin C. J Med Food 2006;9:440-442.

38 Greco E, Iacobelli M, Rienzi L, Ubaldi F, Ferrero S, Tesarik J: Reduction of the incidence of sperm DNA fragmentation by oral antioxidant treatment. J Androl 2005;26:349-353.

39 Cyrus A, Kabir A, Goodarzi D, Moghimi M: The effect of adjuvant vitamin C after varicocele surgery on sperm quality and quantity in infertile men: a double blind placebo controlled clinical trial. Int Braz J Urol 2015;41:230-238.

40 Mangoli E, Talebi AR, Anvari M, Taheri F, Vatanparast M, Rahiminia T, Hosseini A: Vitamin C attenuates negative effects of vitrification on sperm parameters, chromatin quality, apoptosis and acrosome reaction in neat and prepared normozoospermic samples. Taiwan J Obstet Gynecol 2018;57:200-204.

41 Hughes CM, Lewis SE, McKelvey-Martin VJ, Thompson W: The effects of antioxidant supplementation during Percoll preparation on human sperm DNA integrity. Hum Reprod 1998;13:1240-1247.

42 Fanaei H, Khayat S, Halvaei I, Ramezani V, Azizi Y, Kasaeian A, Mardaneh J, Parvizi MR, Akrami M: Effects of ascorbic acid on sperm motility, viability, acrosome reaction and DNA integrity in teratozoospermic samples. Iran J Reprod Med 2014;12:103-110.

43 Organization WH: WHO laboratory manual for the examination and processing of human semen. 2010

44 Misro MM, Choudhury L, Upreti K, Gautam D, Chaki SP, Mahajan AS, Babbar R: Use of hydrogen peroxide to assess the sperm susceptibility to oxidative stress in subjects presenting a normal semen profile. Int J Androl 2004;27:82-87.

45 Chaki SP, Misro MM: Assessment of human sperm function after hydrogen peroxide exposure. development of a vaginal contraceptive. Contraception 2002;66:187-192.

46 Rato L, Duarte AI, Tomás GD, Santos MS, Moreira PI, Socorro S, Cavaco JE, Alves MG, Oliveira PF: Prediabetes alters testicular PGC1- $\alpha$ /SIRT3 axis modulating mitochondrial bioenergetics and oxidative stress. Biochim Biophys Acta 2014;1837:335-344.

47 Benzie IF, Strain JJ: The ferric reducing ability of plasma (FRAP) as a measure of "antioxidant power": the FRAP assay. Anal Biochem 1996;239:70-76.

48 Moretti E, Mazzi L, Terzuoli G, Bonechi C, Iacoponi F, Martini S, Rossi C, Collodel G: Effect of quercetin, rutin, naringenin and epicatechin on lipid peroxidation induced in human sperm. Reprod Toxicol 2012;34:651657.

49 Ben Abdallah F, Zribi N, Ammar-Keskes L: Antioxidative potential of Quercetin against hydrogen peroxide induced oxidative stress in spermatozoa in vitro. Andrologia 2011;43:261-265.

50 Benzie IFF, Devaki M: The ferric reducing/antioxidant power (FRAP) assay for non-enzymatic antioxidant capacity: concepts, procedures, limitations and applications; in Apak R, Çapanoglu E, Shahidi F (eds): Measurement of Antioxidant Activity \& Capacity, Wiley, 2018, pp 77-106.

51 Ahmad G, Agarwal A, Esteves SC, Sharma R, Almasry M, Al-Gonaim A, AlHayaza G, Singh N, Al Kattan L, Sannaa WM, Sabanegh E: Ascorbic acid reduces redox potential in human spermatozoa subjected to heatinduced oxidative stress. Andrologia 2017;49:e12773.

52 Karabulut S, Korkmaz O, Erdem Altun C, Demiroğlu Zergeroğlu A, Keskin İ: Quercetin enhances human sperm motility in a dose and time dependent manner. Acta Pharm Sci 2020; DOI: 10.23893/1307-2080. APS.05810.

53 Evdokimov VV, Barinova KV, Turovetskii VB, Muronetz VI, Schmalhausen EV: Low concentrations of hydrogen peroxide activate the antioxidant defense system in human sperm cells. Biochemistry (Moscow) 2015;80:1178-1185.

54 Kurkowska W, Bogacz A, Janiszewska M, Gabryś E, Tiszler M, Bellanti F, Kasperczyk S, Machoń-Grecka A, Dobrakowski M, Kasperczyk A: Oxidative Stress is Associated with Reduced Sperm Motility in Normal Semen. Am J Mens Health 2020;14:1557988320939731.

55 Walters JLH, De Iuliis GN, Nixon B, Bromfield EG: Oxidative Stress in the Male Germline: A Review of Novel Strategies to Reduce 4-Hydroxynonenal Production. Antioxidants (Basel) 2018;7:132.

56 Moazamian R, Polhemus A, Connaughton H, Fraser B, Whiting S, Gharagozloo P, Aitken R: Oxidative stress and human spermatozoa: Diagnostic and functional significance of aldehydes generated as a result of lipid peroxidation. Mol Hum Reprod 2015;21:502-515.

57 Nowicka-Bauer K, Nixon: Molecular Changes Induced by Oxidative Stress that Impair Human Sperm Motility. Antioxidants 2020;9:134. 


\section{Cellular Physiology Cell Physiol Biochem 2022;56(S1):1-23

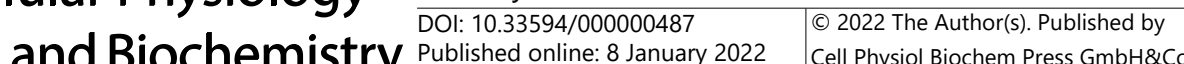 and Biochemistry Published online: 8 January 2022 Cell Physiol Biochem Press GmbH\&Co. KG \\ Moreira et al.: Vitamin $\mathrm{C}$ and Hyperoside Protect Human Spermatozoa}

58 Raad G, Mansour J, Ibrahim R, Azoury J, Azoury J, Mourad Y, Fakih C, Azoury J: What are the effects of vitamin $C$ on sperm functional properties during direct swim-up procedure? Zygote 2019;27:69-77.

59 Li Z, Lin Q, Liu R, Xiao W, Liu W: Protective effects of ascorbate and catalase on human spermatozoa during cryopreservation. J Androl 2010;31:437-444.

60 du Plessis SS, Agarwal A, Mohanty G, van der Linde M: Oxidative phosphorylation versus glycolysis: what fuel do spermatozoa use? Asian J Androl 2015;17:230-235.

61 Nascimento JM, Shi LZ, Tam J, Chandsawangbhuwana C, Durrant B, Botvinick EL, Berns MW: Comparison of glycolysis and oxidative phosphorylation as energy sources for mammalian sperm motility, using the combination of fluorescence imaging, laser tweezers, and real-time automated tracking and trapping. J Cell Physiol 2008;217:745-751.

62 Gallon F, Marchetti C, Jouy N, Marchetti P: The functionality of mitochondria differentiates human spermatozoa with high and low fertilizing capability. Fertil Steril 2006;86:1526-1530.

63 Ferramosca A, Provenzano SP, Coppola L, Zara V: Mitochondrial Respiratory Efficiency is Positively Correlated With Human Sperm Motility. Urology 2012;79:809-814.

64 Gray LR, Tompkins SC, Taylor EB: Regulation of pyruvate metabolism and human disease. Cell Mol Life Sci 2014;71:2577-2604.

65 Mitchell M, Cashman KS, Gardner DK, Thompson JG, Lane M: Disruption of Mitochondrial Malate-Aspartate Shuttle Activity in Mouse Blastocysts Impairs Viability and Fetal Growth1. Biol Reprod 2009;80:295-301.

66 Newsholme P, Keane K, Homem de Bittencourt Jr P, Krause M: The Impact of Inflammation on Pancreatic $\beta$-Cell Metabolism, Function and Failure in T1DM and T2DM: Commonalities and Differences, in Escher AP, Li A (eds): Type 1 Diabetes, InTech, 2013, pp 127-165.

67 Deburgos NG, Gallina F, Burgos C, Blanco A: Effect of L-malate on pyruvate-dehydrogenase activity of spermatozoa. Arch Biochem Biophys 1994;308:520-524.

68 Storey BT, Kayne FJ: Energy metabolism of spermatozoa. VII. Interactions between lactate, pyruvate and malate as oxidative substrates for rabbit sperm mitochondria. Biol Reprod 1978;18:527-536.

69 Bose S, Ramesh V, Locasale JW: Acetate Metabolism in Physiology, Cancer, and Beyond. Trends Cell Biol 2019;29:695-703.

70 Alves M, Socorro S, Silva J, Barros A, Sousa M, Cavaco J, Oliveira PJBeba: In vitro cultured human Sertoli cells secrete high amounts of acetate that is stimulated by $1:^{2}$-estradiol and suppressed by insulin deprivation. Biochim Biophys Acta 2012;1823 8:1389-1394.

71 Carrageta DF, Guerra-Carvalho B, Sousa M, Barros A, Oliveira PF, Monteiro MP, Alves MG: Mitochondrial Activation and Reactive Oxygen-Species Overproduction during Sperm Capacitation are Independent of Glucose Stimuli. Antioxidants 2020;9

72 Zribi N, Chakroun NF, Ben Abdallah F, Elleuch H, Sellami A, Gargouri J, Rebai T, Fakhfakh F, Keskes LA: Effect of freezing-thawing process and quercetin on human sperm survival and DNA integrity. Cryobiology 2012;65:326-331.

73 Seifi-Jamadi A, Kohram H, Zare Shahneh A, Ansari M, Macías-García B: Quercetin Ameliorate Motility in Frozen-Thawed Turkmen Stallions Sperm. J Equine Vet Sci 2016;45:73-77.

74 Najafi A, Kia HD, Mehdipour M, Hamishehkar H, Álvarez-Rodríguez M: Effect of quercetin loaded liposomes or nanostructured lipid carrier (NLC) on post-thawed sperm quality and fertility of rooster sperm. Theriogenology 2020;152:122-128.

75 Avdatek F, Yeni D, İnanç ME, Çil B, Tuncer BP, Türkmen R, Taşdemir U: Supplementation of quercetin for advanced DNA integrity in bull semen cryopreservation. Andrologia 2018;50:e12975.

76 Sierens J, Hartley J, Campbell M, Leathem A, Woodside J: In vitro isoflavone supplementation reduces hydrogen peroxide-induced DNA damage in sperm. Teratog Carcinog Mutagen 2002;22:227-234.

77 Calvert SJ, Reynolds S, Paley MN, Walters SJ, Pacey AA: Probing human sperm metabolism using 13C-magnetic resonance spectroscopy. Mol Hum Reprod 2019;25:30-41.

78 Reynolds S, Ismail NFb, Calvert SJ, Pacey AA, Paley MNJ: Evidence for Rapid Oxidative Phosphorylation and Lactate Fermentation in Motile Human Sperm by Hyperpolarized 13C Magnetic Resonance Spectroscopy. Sci Rep 2017;7:4322.

79 Guarino VA, Oldham WM, Loscalzo J, Zhang Y-Y: Reaction rate of pyruvate and hydrogen peroxide: assessing antioxidant capacity of pyruvate under biological conditions. Sci Rep 2019;9:19568.

80 Desagher S, Glowinski J, Prémont J: Pyruvate protects neurons against hydrogen peroxide-induced toxicity. J Neurosci 1997;17:9060-9067. 


\section{Cellular Physiology Cell Physiol Biochem 2022;56(S1):1-23}

\begin{tabular}{ll|l} 
and Biochemistry & $\begin{array}{l}\text { DOl: 10.33594/000000487 } \\
\text { Published online: } 8 \text { January 2022 }\end{array}$ & $\begin{array}{l}\text { O } 2022 \text { The Author(s). Published by } \\
\text { Cell Physiol Biochem Press GmbH\&Co. KG }\end{array}$ \\
\cline { 2 - 3 }
\end{tabular}

Moreira et al.: Vitamin $\mathrm{C}$ and Hyperoside Protect Human Spermatozoa

81 Babich H, Liebling E, Burger R, Zuckerbraun H, Schuck A: Choice of DMEM, formulated with or without pyruvate, plays an important role in assessing the in vitro cytotoxicity of oxidants and prooxidant nutraceuticals. In vitro Cell Dev Biol Anim 2009;45:226-233.

82 Sheraz M, Khan M, Ahmed S, Kazi S, Ahmad I: Stability and Stabilization of Ascorbic Acid. Househ Pers Care Today 2015;10:20-25.

83 Gallarate M, Carlotti ME, Trotta M, Bovo S: On the stability of ascorbic acid in emulsified systems for topical and cosmetic use. Int J Pharm 1999;188:233-241.

84 Dolińska B, Ostróżka-Cieślik A, Caban A, Rimantas K, Leszczyńska L, Ryszka F: Influence of trace elements on stabilization of aqueous solutions of ascorbic acid. Biol Trace Elem Res 2012;150:509-512.

85 Shi S, Long R, Tang C, Yang z, Fu Q, Xu J, Tong C, Guo Y, Wang D: A natural hyperoside based novel light-up fluorescent probe with AIE and ESIPT characteristics for on-site and long-term imaging of $\beta$-galactosidase in living cells. J Mater Chem C 2020;8:11860-11865. 